\title{
Bimetallic Iron-Cobalt Catalysts and Their Applications in Energy-Related Electrochemical Reactions
}

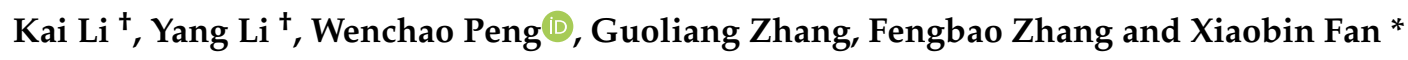 \\ Lab of Advanced Nano Structures \& Transfer Processes, Department of Chemical Engineering, \\ Tianjin University, Tianjin 300354, China; tju_likai@163.com (K.L.); liyang1895@tju.edu.cn (Y.L.); \\ wenchao.peng@tju.edu.cn (W.P.); zhangguoliang@tju.edu.cn (G.Z.); fbzhang@tju.edu.cn (F.Z.) \\ * Correspondence: xiaobinfan@tju.edu.cn; Tel.: +86-022-85356119 \\ + These authors contributed equally to this work.
}

Received: 19 August 2019; Accepted: 5 September 2019; Published: 11 September 2019

\begin{abstract}
Since the persistently increasing trend of energy consumption, technologies for renewable energy production and conversion have drawn great attention worldwide. The performance and the cost of electrocatalysts play two crucial roles in the globalization of advanced energy conversion devices. Among the developed technics involving metal catalysts, transition-metal catalysts (TMC) are recognized as the most promising materials due to the excellent properties and stability. Particularly, the iron-cobalt bimetal catalysts exhibit exciting electrochemical properties because of the interior cooperative effects. Herein, we summarize recent advances in iron-cobalt bimetal catalysts for electrochemical applications, especially hydrogen evolution reaction (HER), oxygen evolution reaction (OER), and oxygen reduction reaction (ORR). Moreover, the components and synergetic effects of the composites and catalytic mechanism during reaction processes are highlighted. On the basis of extant catalysts and mechanism, the current issues and prospective outlook of the field are also discussed.
\end{abstract}

Keywords: energy conversion; iron-cobalt bimetal catalysts; electrochemical application; hydrogen evolution; oxygen evolution; oxygen reduction

\section{Introduction}

Growing depletion of fossil fuels and rapid increase of pollution pose new challenges to the environment and ecosystem. It is urgent to explore renewable and sustainable energy as a substitute to traditional energy sources to balance the economic and ecological development. Among the related technologies, energy storage and conversion devices are needed and widely concentrated. In the past decades, a series of potential electrochemical energy storage and conversion facilities such as fuel cells, water splitting technologies, and metal-air batteries have been deeply investigated, which can significantly decrease the reliance on traditional fossil fuels and promote energy conversion efficiency [1]. Electrocatalytic reactions, like hydrogen evolution reaction (HER), oxygen evolution reaction (OER), and oxygen reduction reaction (ORR), play vital roles in these electrochemical techniques. For example, water splitting demands high HER and OER activities, in which the cathodic reaction is $\mathrm{HER}\left(4 \mathrm{H}^{+}+\right.$ $4 \mathrm{e}^{-} \rightarrow 2 \mathrm{H}_{2}$ in acid, $4 \mathrm{H}_{2} \mathrm{O}+4 \mathrm{e}^{-} \rightarrow 2 \mathrm{H}_{2}+4 \mathrm{OH}^{-}$in alkali) while the anodic reaction is OER $\left(2 \mathrm{H}_{2} \mathrm{O} \rightarrow \mathrm{O}_{2}\right.$ $+4 \mathrm{H}^{+}+4 \mathrm{e}^{-}$in acid, $4 \mathrm{OH}^{-} \rightarrow \mathrm{O}_{2}+2 \mathrm{H}_{2} \mathrm{O}+4 \mathrm{e}^{-}$in alkali). Meanwhile, rechargeable metal-air batteries require OER in the charging process and ORR $\left(\mathrm{O}_{2}+4 \mathrm{H}^{+}+4 \mathrm{e}^{-} \rightarrow 2 \mathrm{H}_{2} \mathrm{O}, 4 \mathrm{e}^{-}\right.$pathway, $\mathrm{O}_{2}+2 \mathrm{H}^{+}+2 \mathrm{e}^{-}$ $\rightarrow \mathrm{H}_{2} \mathrm{O}_{2}$ ) in the discharging process. Developing electrocatalysts of high efficiency and low cost is the main obstruction to break through the limit of the sluggish dynamics of such reactions [2]. Up to now, the noble metals, like platinum (Pt), iridium ( $\mathrm{Ir})$, and ruthenium $(\mathrm{Ru})$ and their derivatives have 
presented favorable catalytic activities, where Pt-based materials show excellent activity for both HER and ORR, and Ir-based and Ru-based catalysts are more active for OER. However, the scarcity and high cost of the noble metals severely limit their large-scale applications and commercial promotions. In this regard, it is necessary to develop nonprecious metals and their derivatives with high efficiency and long-term stability as promising candidates for electrocatalysis.

Currently, the $3 \mathrm{~d}$ transition nonnoble metals, especially $\mathrm{Fe}, \mathrm{Co}$, and $\mathrm{Ni}$ and their derivatives, have been regarded as the most promising substitute to the noble metals like Pt because of their high catalytic activities to the energy conversion reactions [3]. However, bare $3 \mathrm{~d}$ transition metal materials are not active or even stable enough to catalyze the electrochemical reactions for long-term operation under acid or alkaline condition. On the contrary, the bimetallic catalysts can make use of the synergistic effects between the metal contents themselves and the supports, thus exhibiting favorable reaction kinetics with high activity and efficiency. Theoretically, the related calculation results, such as density functional theory calculation (DFT), have also proved that the bimetallic electrocatalysts perform better than the monometallic ones. The calculated $\Delta \mathrm{G}$ of the single $3 \mathrm{~d}$ transition metallic materials to develop intermediates during the reactions is much further from the optimal value than the precious metals. Therefore, designing bimetallic catalysts can modify the $\Delta \mathrm{G}$ of the single metallic catalysts and improve the catalytic efficiency. Recently, the bimetallic materials combining Fe and Co or their derivatives and their electrochemical applications have been investigated by researchers. Numerous studies have been devoted to the bimetallic electrocatalysts, such as alloys [4], oxides [5], hydroxides [6], sulfides [7], phosphides [8], and hierarchical structures. The strategies to construct the materials and the electronic modulations inside have been also deeply researched. By both calculative and experimental approaches, the kinetics and mechanisms during the catalytic processes are also explored.

In this review, we summarized recent development of the Fe-Co bimetal electrocatalysts and their electrochemical applications, with the focus on both the constructive strategies and the catalytic mechanisms. The synthesized materials are categorized by the structural characteristics and the preparation process, followed by an inductive section of the characterization methods. The electrochemical applications are then discussed, which mainly concentrated on electrochemical HER, OER, and ORR. The relation between the structures and the catalytic properties is highlighted and elaborated emphatically. By this work, we aim to give a summarization of the bimetallic electrocatalysts containing $\mathrm{Fe}$ and $\mathrm{Co}$, so as to update the conception of the electrocatalytic kinetics for the aforementioned electrochemical reactions.

\section{Synthesis Methods for Fe/Co Bimetallic Catalysts}

The catalyst supports in the hybrid materials affect the electronic and surface structure, shape, size, and decide the accessible active sites and the mass transfer rate during the reaction process and the accessible part of the active sites; hence, they largely control the electrocatalytic activity. Such a strategy is found to be prospective for the three essential requirements for an electrocatalysts' activity, as it can simultaneously ensure abundant active site densities, controllable performance characteristics, and reactant accessibility by narrowing down the overpotential and enhancing the current density. We present the synthesis process of the Fe-Co bimetal hybrids into three categories based on the catalyst supports, as bimetallic alloy-based hybrid, carbon materials supported bimetallic hybrid, and metal-organic frameworks (MOF)-based bimetallic hybrid catalysts.

\subsection{Bimetallic Alloy-Based Hybrid Catalysts}

Fe-Co bimetallic alloys [9] exhibit multifarious structural, mechanical, optical, electronic, and electrocatalytic properties. Spherical, uniform, and highly monodisperse Fe-Co nanoparticles with different metal content ratios were synthesized through the microemulsion method [4]. The microemulsions of metal salt precursors, reducing agent, and surfactants were annealed in $\mathrm{H}_{2}$ atmosphere at $700{ }^{\circ} \mathrm{C}$ for $6 \mathrm{~h}$ and formed monophasic bimetallic nanoparticles. The average sizes of the obtained nanoparticles vary with the initial loaded stoichiometries of Fe and Co metal precursors. 
Meanwhile, the oxidation currents obtained by cyclic voltammetry are a function of both the surface area and the composition of the bimetallic nanoparticles, illustrating that the $\mathrm{Fe}_{33} \mathrm{Co}_{67}$ nanoparticles are of superior hydrogen and oxygen evolution activity.

The positively charged layered hydroxide sheets formed by tilted edge-sharing $\mathrm{MO}_{6}$ octahedra and negatively charged counterions in the interlayers are namely layered double hydroxides (LDHs), with intrinsic OER activity according to the abundance tetrahedral $\mathrm{Co}^{2+}$, octahedral $\mathrm{Co}^{3+}$, and oxygen vacancies on the high surface sheet of two-dimensional materials [10,11]. A platelet-like-shaped Fe substituted $\alpha-\mathrm{Co}(\mathrm{OH})_{2}$ was synthesized under a $\mathrm{N}_{2}$ atmosphere at room temperature [12]. To reach an equivalent number of anions, Fe (III) ions replaced some $\mathrm{Co}$ (II) ions in $\alpha-\mathrm{Co}(\mathrm{OH})_{2}$ by the interaction within the edge sharing $\mathrm{MO}_{6}(\mathrm{M}=\mathrm{Co}$ or $\mathrm{Fe})$ octahedral layers, resulting in the formation of CoFe $\mathrm{LDH}$ structure. Similar CoFe- and CoAl-based LDH catalysts with various $\mathrm{Fe}$ and $\mathrm{Al}$ contents were also fabricated by an efficient coprecipitation method $[13,14]$. The Fe impurity makes $\mathrm{OH}^{-}$intercalation easier in facilitating $\mathrm{Co}(\mathrm{OH})_{2}+\mathrm{OH}^{-} \rightarrow \mathrm{CoOOH}+\mathrm{H}_{2} \mathrm{O}+\mathrm{e}^{-}$. Herein, the incorporation of Fe into the layered (oxy)hydroxide structure may accelerate interlayer spacing of the sheets, as well as the defect or edge sites on the Co oxyhydroxide structure. The appearance of the low-angle reflection for the Co-Fe phase in the X-ray diffraction (XRD) pattern is the evidence for such incorporation [14]. Considering the strong electronic coactions between $\mathrm{Co}$ and $\mathrm{Fe}$, the alternation of $\mathrm{Co} / \mathrm{Fe}$ ratio during the CoFe-based LDHs synthesis process may change the situation of $\mathrm{Fe}^{3+}$ cations substituted into the lattice of $\alpha-\mathrm{Co}(\mathrm{OH})_{2}$, modifying the electronic structure of the catalyst and the formation of LDH structure $[15,16]$. The facile synthesized process takes advantage of the chemically stable and areal layered structure, good conductivity of $\alpha-\mathrm{Co}(\mathrm{OH})_{2}$, as well as the rich redox properties and earth abundance of $\mathrm{Fe}$, substantially facilitating low-cost clean energy production.

Metal borides are known as the newly developed OER catalysts, as the boron can drop off the M-M bonds and cut down the thermodynamic and kinetic barrier in the rate-limiting step during OER [17]. A bimetallic $\mathrm{CO}_{x}-\mathrm{Fe}-\mathrm{B}$ catalyst, with the average particle size of about $30 \mathrm{~nm}$, was synthesized by the reduction of sodium borohydride and sodium hydroxide solution under whisking at room temperature [18]. Through this chemical reduction method, Fe has been successfully incorporated into the $\mathrm{Co}-\mathrm{B}$, resulting in the stabilization of $\mathrm{Co}$ at a higher oxidation level and the generation of $\mathrm{OOH}$-like species.

The influence of non-metal elements doping in the transition metal-based materials are also investigated through bifunctional electrocatalytic application of phosphorus-doped Co-Fe-B material [19]. Co and Fe chlorides with different molar ratios are solved in polyvinyl pyrrolidone (PVP) and $\mathrm{NaBH} 4$, which serve as surfactant and reducing agent. One-dimensional phosphorous-doped $\mathrm{Co}-\mathrm{Fe}-\mathrm{B}(\mathrm{Co}-\mathrm{Fe}-\mathrm{B}-\mathrm{P})$ nanochains were synthesized via a low-temperature phosphorization procedure of annealing in $\mathrm{Ar}$ atmosphere to $300{ }^{\circ} \mathrm{C}$ for $2 \mathrm{~h}$ (Figure 1). The XRD pattern of the obtained $\mathrm{Co}-\mathrm{Fe}-\mathrm{B}-\mathrm{P}$ materials illustrates the amorphous nature, which exhibit higher electrochemical activities compared with the corresponding crystalline material [20]. The structure comparation of bimetal borides and mono-metal counterparts verifies that Co plays a major role in morphology control. The synergistic effect of different metals and nonmetal components incorporation are characterized by XPS and electrochemical application, which is beneficial for lowering the kinetic energy barriers of electrocatalysis and improving the activity. The one-dimensional chain-like nanostructures possessing high aspect ratio and easy surface atoms contribute to the high OER electrocatalytic activity [21]. 


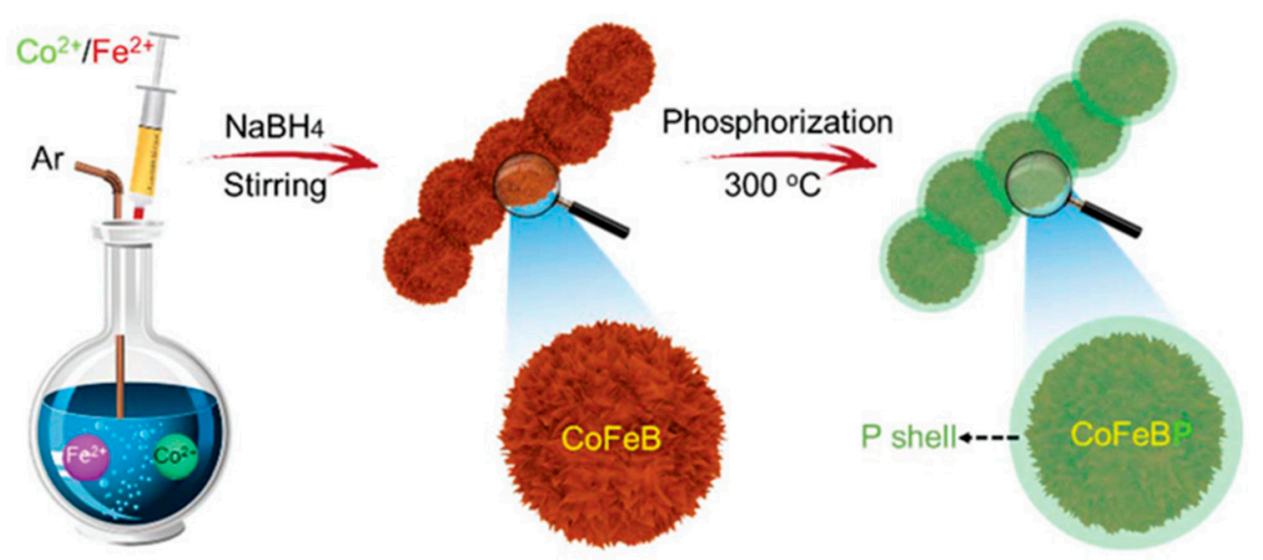

Figure 1. Schematic synthesis process of the $\mathrm{Co}_{1}-\mathrm{Fe}_{1}-\mathrm{B}-\mathrm{P}$ nanochains, reproduced with permission from [19]. Copyright Royal Society of Chemistry, 2019.

\subsection{Carbon Materials Supported Bimetallic Hybrid Catalysts}

Dispersing metal particles on appropriate supports is an efficient strategy to improve the catalytic performance and further reduce the production cost. Large-area conductive substrates, carbon-based materials, such as graphene, are favorable for ameliorating the materials' electronic conductivity and dispersion in order to promote the electrocatalytic activity. Such carbon-based materials take on unique expediency for assigned catalysis owing to their accessibility, tunable structures, and good resilience in acidic and basic environments.

\subsubsection{Graphene-Based Bimetallic Hybrid Catalysts}

The two-dimensional material functionalized as the catalyst support can not only increase the quantity of accessible active sites by minimizing the particle sizes, but also manipulate the electronic properties of the obtained metal particles, thus leading to the amelioration in instinct catalytic activity of the hybrid materials. On the other hand, the mesoporous structure and large specific surface area in the graphene-based materials are in favor of the high exposure of active sites, fasten the mass transport of the reactants, as well as fabricate conducting networks for fast electron transfer during the whole reaction process.

Hydrothermal and solvothermal treatment of the metal precursor and graphene oxide are the general approaches to synthesize metal nanoparticles embedded graphene framework [22,23]. $\mathrm{Wu}$ et al. [7] decorated cobalt sulfide $\left(\mathrm{Co}_{9} \mathrm{~S}_{8}\right)$ nanoparticles grown in situ on the reduced graphene oxide surface with $\mathrm{Fe}_{3} \mathrm{O}_{4}$ nanoparticles in two solvothermal steps. In the first step, $\mathrm{Co}_{9} \mathrm{~S}_{8}$ nanoparticles are formed onto reduced graphene oxide nanosheets. Then, iron ions are selectively adsorbed on the surface of $\mathrm{Co}_{9} \mathrm{~S}_{8}$ by forming the strong bonding of sulfur species, and subsequently reduced to $\mathrm{Fe}_{3} \mathrm{O}_{4}$ at $600{ }^{\circ} \mathrm{C}$. The interface-orientation relationship determined by HRTEM illustrates the loading of $\mathrm{Fe}_{3} \mathrm{O}_{4}$ on the surface of $\mathrm{Co}_{9} \mathrm{~S}_{8}$ and may induce a relatively high stability of the composite. It has been demonstrated that the breaking of the $\mathrm{Co}-\mathrm{O}$ bond in the stable configure ration $(\mathrm{Co}-\mathrm{O}-\mathrm{O}$ superoxo group) to free the $\mathrm{O}_{2}$ molecules may represent a rate-limiting step [24]. Electron transfer behavior from Fe species to $\mathrm{Co}_{9} \mathrm{~S}_{8}$, causing the down-shift in the electron binding energy of $\mathrm{Co}_{2} \mathrm{p}_{3 / 2}$, may induce a relatively lower oxidation state for cobalt ions, which would promote the $\mathrm{Co}-\mathrm{O}$ bond break and the $\mathrm{O}_{2}$ release, and improve the catalytic activity.

Considering the possible structural damage during the high-temperature treatment, a conversion tailoring strategy was designed to assemble nanometer-sized Fe-modulated $\mathrm{CoOOH}$ nanoparticles $(\mathrm{Fe}-\mathrm{CoOOH})$ on $2 \mathrm{D}$ graphene in a mild synthesis process [25]. The CoFeAl-layered double hydroxide (CoFeAl-LDH) sheets in situ grow on the GO surface by the electrostatic interactions with metal ions. The Fe components of ultrasensitive triggered behavior would restrict the process for the structural rearrangement toward $\mathrm{Co}(\mathrm{OH})_{2}$ and oxidize to $\mathrm{CoOOH}$ and yield the $\mathrm{Fe}-\mathrm{CoOOH}$ nanoparticles. 
Such a process indicates the chemical selective accelerative conversion led by Fe. According to DFT calculation, the adsorption energies of $\mathrm{OH}, \mathrm{OOH}$, and $\mathrm{O}$ species are remarkably enhanced at the $\mathrm{Fe}$ sites and decreased at the $\mathrm{Co}$ sites of $\mathrm{Fe}-\mathrm{CoOOH}$, facilitating the whole redox reactions and enhancing the catalytic activity of the hybrids.

The introduction of chemical functionalities through chemical functionalization and heteroatom (non-metal elements such as N, S, B, F, and P) may improve not only the immobilization of different species, but also the electrocatalytic activity by tuning the band gap and electronic structure (for instance, charge and/or spin density redistribution) of carbon to increase the active sites density towards favorable water splitting reactions. The synergistic effect between the transition metal/metal oxide and heteroatom-doped carbon along with the enhanced electronic conductivity may largely improve the ORR and OER kinetics [26]. Wang et al. [27] reported the method of combining ball milling and pyrolysis to fabricate FeCo nanoparticles/N-doped carbon with core-shell structure spheres supported on N-doped graphene sheets (Figure 2). The ball-milling process was carried out with carbon nitride $\left(\mathrm{C}_{3} \mathrm{~N}_{4}\right)$ and metal acetylacetonates, followed by the pyrolysis step at $700{ }^{\circ} \mathrm{C}$. The acetylacetonates were decomposed to acetone and carbon dioxide and adsorbed on $\mathrm{C}_{3} \mathrm{~N}_{4}$, then transferred to graphene as the supporter. The change of pyrolysis temperature led to the structure alteration of layered graphitic carbon encapsulated in the FeCo nanoparticles and the growth of carbon nanotubes on graphene surface [28]. Pyridinic-N and graphitic-N in carbon produced during pyrolysis can decline the adsorption energy of $\mathrm{O}_{2}$ owing to the $\mathrm{N}$ doping-induced charge redistribution and have been pointed out to be the efficient active sites for ORR. The synergy of $\mathrm{N}$-doped carbon shell-covered $\mathrm{FeCo}$ bimetallic nanoparticles, the suitable pore structure, along with the graphene supporter facilitate the reactant transport and promote charge transfer during the reaction.

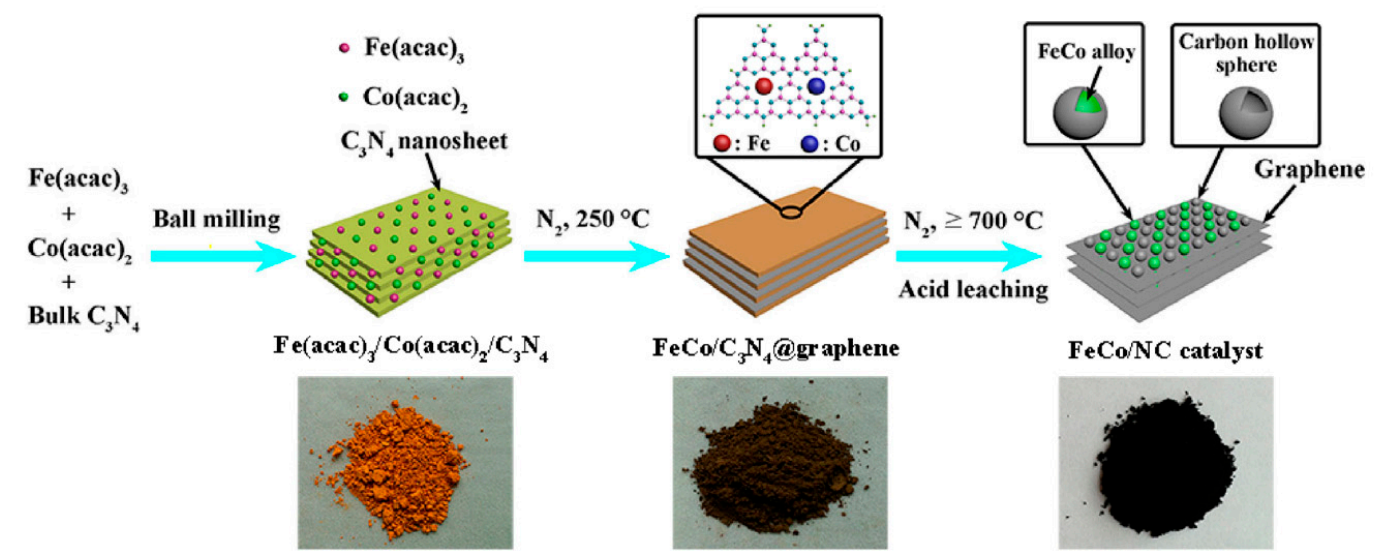

Figure 2. Schematic illustration synthesis process of $\mathrm{FeCo} / \mathrm{NC}$ catalysts from $\mathrm{Fe}(\mathrm{acac})_{2}, \mathrm{Co}(\mathrm{acac})_{2}$, and bulk $\mathrm{C}_{3} \mathrm{~N}_{4}$, reproduced with permission from [27]. Copyright Springer nature, 2017.

Quantum confinement effect along with edge effect are other efficient methods in controlling the band gap of graphene, which may make graphene materials compatible for direct exploitation in nanoelectronics [29]. The introduction of nanoholes on graphene sheet may increase the defects and dangling bonds of edge sites as the appropriate active sites for the heteroatom doping [30], as well as promote the reactant ions diffusion to the active sites to enhance the catalytic activity in the reaction. Herein, nano-porous graphene has been applied as the support for metal carbides to fabricate $\mathrm{Fe} / \mathrm{CoN}$-doped porous graphene by annealing at $900{ }^{\circ} \mathrm{C}$ (Figure 3) [31]. A chemically assisted oxidative treatment of graphene is used to break small pieces through epoxide formation and prepare porous graphene with more edged sites [32]. The TEM and XRD analyze that the pyrolysis of the M-phenanthroline ( $\mathrm{M}-\mathrm{Fe}$ and $\mathrm{Co}$ ) complexes with graphene at $900{ }^{\circ} \mathrm{C}$ leads to the generation of the $\mathrm{M}-\mathrm{N}-\mathrm{C}$ active sites along with the metallic or carbide phases. The obtained hybrids have homogeneously distributed $\mathrm{Fe} / \mathrm{Co}-\mathrm{N}$-doped active centers, which confirms that the uniform 
distribution of nanoholes plays a vital role in enriching the coordinated active sites on the graphene surface, enhancing mass transfer and modulating reaction kinetics. Such high activity of the obtained catalyst highlights the important role of the active $\mathrm{M}-\mathrm{N}-\mathrm{C}$ coordinations conceived in the hybrids as the potential ORR active centers. By comparing the ORR activity with its single metallic counterpart, the $\mathrm{Fe} / \mathrm{CoN}$-doped porous graphene show higher catalytic activity by taking advantage of the existence of the bimetallic coordinated sites in the company of the existence of the nanopores on graphene surface. The electrocatalytic test results likewise illustrate that the pyrolysis of the mixture containing the metal macrocyclic complexes and suitable carbon nanomaterials could be the appropriate method for preparing effective $\mathrm{M}-\mathrm{N}-\mathrm{C}$ electrocatalysts for ORR rather than developing harmonious cooperation of the metal ions and doped nitrogen in the carbon matrix.

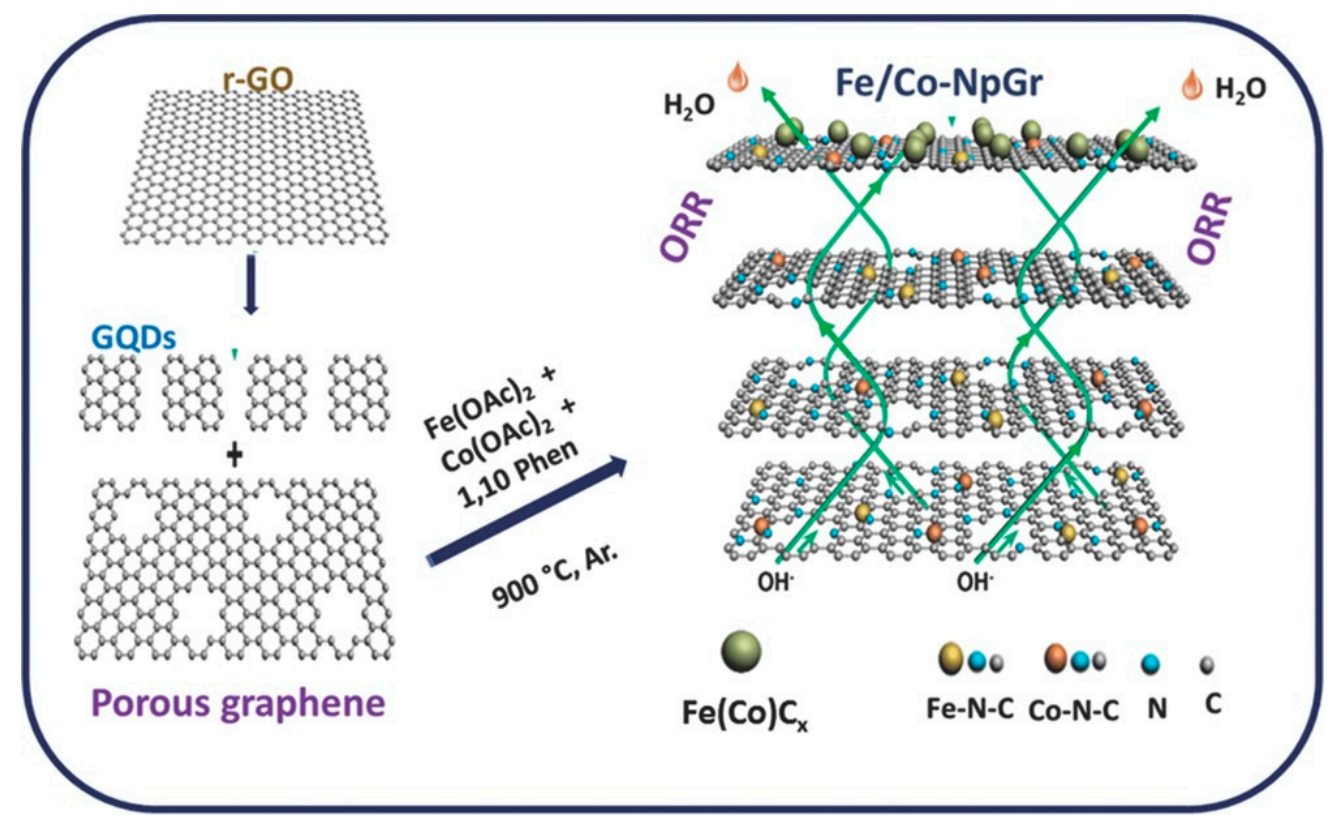

Figure 3. The scheme of the preparation of active $\mathrm{Fe} / \mathrm{Co}-\mathrm{NpGr}$ representing facile ion transport attainable within the hybrids through the holes in the porous graphene, which may enhance the accessibility of the active sites and lead to improved oxygen reduction reaction (ORR) activity, reproduced with permission from [31]. Copyright Wiley, 2016.

Aforementioned graphene-based electrocatalysts are of a high surface area to volume ratio. Indeed, only a small fraction of metal nanoparticles is exposed to reactants in such materials. Herein, promoting the metal atom utilization of a catalyst is an incredibly effective way to further improve the catalytic activity. $100 \%$ atom utilization efficiency by featured atomically dispersed metal atoms as robust active centers is of long-standing interest in fabricating catalysts. The latest development of fabricating single-atom catalysts (SACs) [33-35] with atomic-scale metal catalytic center, making individual metal atoms accessible and active, is a possible method for maximizing the atom efficiency. Ball milling is one of the low-cost and high-efficiency exfoliation and functionalization methods for establishing graphene-based SACs. Wu et al. [36] synthesized highly dispersed $\mathrm{Fe} / \mathrm{Co} / \mathrm{N}$ on graphene through a one-step ball milling protocol in $12 \mathrm{~h}$. Many defective sites may appear during the ball milling process and facilitate the heteroatom doping. The existence of metal-bonded $\mathrm{N} / \mathrm{O}$, which are taken for the efficient active sites for OER [37], are confirmed by XPS characterization. The electrocatalytic activity results also show that the electrochemical surface area (ESCA) and valid active sites of the obtained hybrids are substantially augmented after ball milling and heteroatom doping, resulting in greatly ameliorating the OER performance. 


\subsubsection{Other Carbon Materials Supported Bimetallic Hybrid Catalysts}

Raj et al. [38] used a single-step thermal annealing approach of potassium cobalt hexacyanoferrate (KCoHCF) to synthesize FeCo bimetal nanoparticle decorating on the nitrogen-doped reduced graphene oxide (N-rGO-CoFe) and graphitic carbon ( $\mathrm{N}-\mathrm{C}-\mathrm{CoFe})$, and discuss the effect of catalyst support on the overall water splitting performance. Compared with that thermal annealing with graphene oxide, the $\mathrm{N}-\mathrm{C}-\mathrm{CoFe}$ hybrids have the structure of a carbon shell strongly coupled with bimetal nanoparticles and high graphitization degree, which ensure the durability of the obtained catalyst. The electrocatalytic activities of the catalysts on different supports confirm that the chemical nature of nitrogen and degree of graphitization of the catalyst largely support control of the overall performance of the catalyst. The higher graphitization of the carbon $\left(\mathrm{sp}^{2} \mathrm{C}-\mathrm{C}\right)$ support containing a larger amount of graphitic nitrogen, the better performance the catalyst has for OER and ORR.

One-dimensional mesoporous $\mathrm{Fe} / \mathrm{Co}-\mathrm{N}-\mathrm{C}$ nanofibers with depositing FeCo nanoparticles (denoted as FeCo@MNC) were synthesized through an electrospinning process [39] of Fe and Co 2, 2-bipyridine chelates, PAN and PVP polymers, following stabilization at $280{ }^{\circ} \mathrm{C}$ in air and carbonization at $900{ }^{\circ} \mathrm{C}$ under $\mathrm{N}_{2}$ [40]. Porous structures of FeCo@MNC with bunch-like nanoparticles embedded on the nanofibers are determined by TEM. Fe and Co appeared both inside and on the surface of the whole nanofibers, implying the simultaneous existing structures of $\mathrm{FeCo}$ and $\mathrm{Fe} / \mathrm{Co}-\mathrm{N}-\mathrm{C}$ in the carbon skeleton. The formation process may be described firstly as formed $\mathrm{Fe}(\mathrm{Co})-\mathrm{N}$ chelates electro-spin with polymers and compose $\mathrm{Fe}(\mathrm{Co})-\mathrm{N}$ and $\mathrm{N}-\mathrm{C}$ structures after carbonization with a high proportion of pyridinic-N structures. Polymers serving as a carbon precursor supplied the perfect template for the fabrication of one-dimensional hollow carbon fibers. The carbon fibers supporting $\mathrm{Fe}, \mathrm{Co}$, and $\mathrm{N}$ show a larger aspect ratio and excellent electrical conductivity, likewise benefitting from active sites exposure and rapid transportation [41].

Another N-doped graphitic carbon nanotube decorated with bimetal FeCo nanoparticles (denoted as $\mathrm{N}-\mathrm{GCNT} / \mathrm{FeCo}$ ) were prepared through temperature-programmed carbonization strategy by pyrolyzing the mixture of metal salt precursors, glutamic acid, and melamine [42] (Figure 4). After the pyrolysis temperature increase, glutamic acid carbonization derives many defects in the graphitic carbon framework, as well as reinforcing $\mathrm{N}$ atoms into the carbon skeleton [41]. The nanotubes with cavities generated through the temperature-controlled carbonization are illustrated by TEM. On account of the strong metal-support interaction, the bimetal alloy nanoparticles catalyze the $\mathrm{N}$-doped graphitic carbon species render into N-GCNT and grow on the inner wall of N-GCNT. The obtained multiphase materials also possess a large specific surface area, with potentially favorable property in the mass transfer during the electrocatalytic reactions.

\subsection{MOF-Based Bimetallic Hybrid Catalysts}

Carbon-based materials encapsulated with transition metals and their alloys have been emerging as promising candidates for water splitting catalysts. Some of the synthesis methods consume complex and expensive multi-step synthesis strategies, delaying the large-scale commercialization. On the other hand, heteroatom doping as mentioned above is an efficient method to accelerate the electrocatalytic activity of the carbon-based materials. Therefore, metal-organic frameworks (MOFs), composed of designable metal ion centers and organic ligands, are the promising precursors for the facile synthesis of metal/metallic alloy@carbon composites via pyrolysis. The easy control of composition, morphology, and construction also endow MOFs with multiple functions and broad applications. Chen et al. [43] carefully designed MOF precursors of desirable metal ion centers and organic ligands with different dopants, to fabricate carbon materials doped by nitrogen cooperating with non-precious metals through one-step annealing (Figure 5). Fe and Co atoms decomposed from the Prussian blue analogues (PBAs, $\left.\mathrm{Fe}_{3}\left[\mathrm{Co}(\mathrm{CN})_{6}\right]_{2}\right)$ precursor form FeCo alloy nanoparticles during the annealing process under $\mathrm{N}_{2}$. Meanwhile, the $\mathrm{CN}^{-}$groups, as double effect carbon and nitrogen sources, form nitrogen-doped graphene layers that cover the FeCo alloy particles. The obtained materials have the FeCo alloys encapsulated in a nitrogen-doped graphene layers structure. The nitrogen content in the material can 
be altered by different annealing temperatures, which may also affect the catalytic activity. The catalyst obtained by annealing at $600{ }^{\circ} \mathrm{C}$ with the highest nitrogen content ( 8.2 atom\%) exhibits the best HER catalytic activity. Such results can be explained by the DFT calculation, as the increase of nitrogen content may accelerate the adsorption sites for $\mathrm{H}^{*}$ and cut down the $\Delta \mathrm{G}_{\mathrm{H}^{*}}$ for $\mathrm{H}$ adsorption at the same time. Peng et al. [44] also chose PBAs as the structural template and fabricated Co-Fe phosphides by etching with urea and phosphorization. The obtained hybrid materials are used as the bifunctional electrocatalyst materials for overall water splitting.
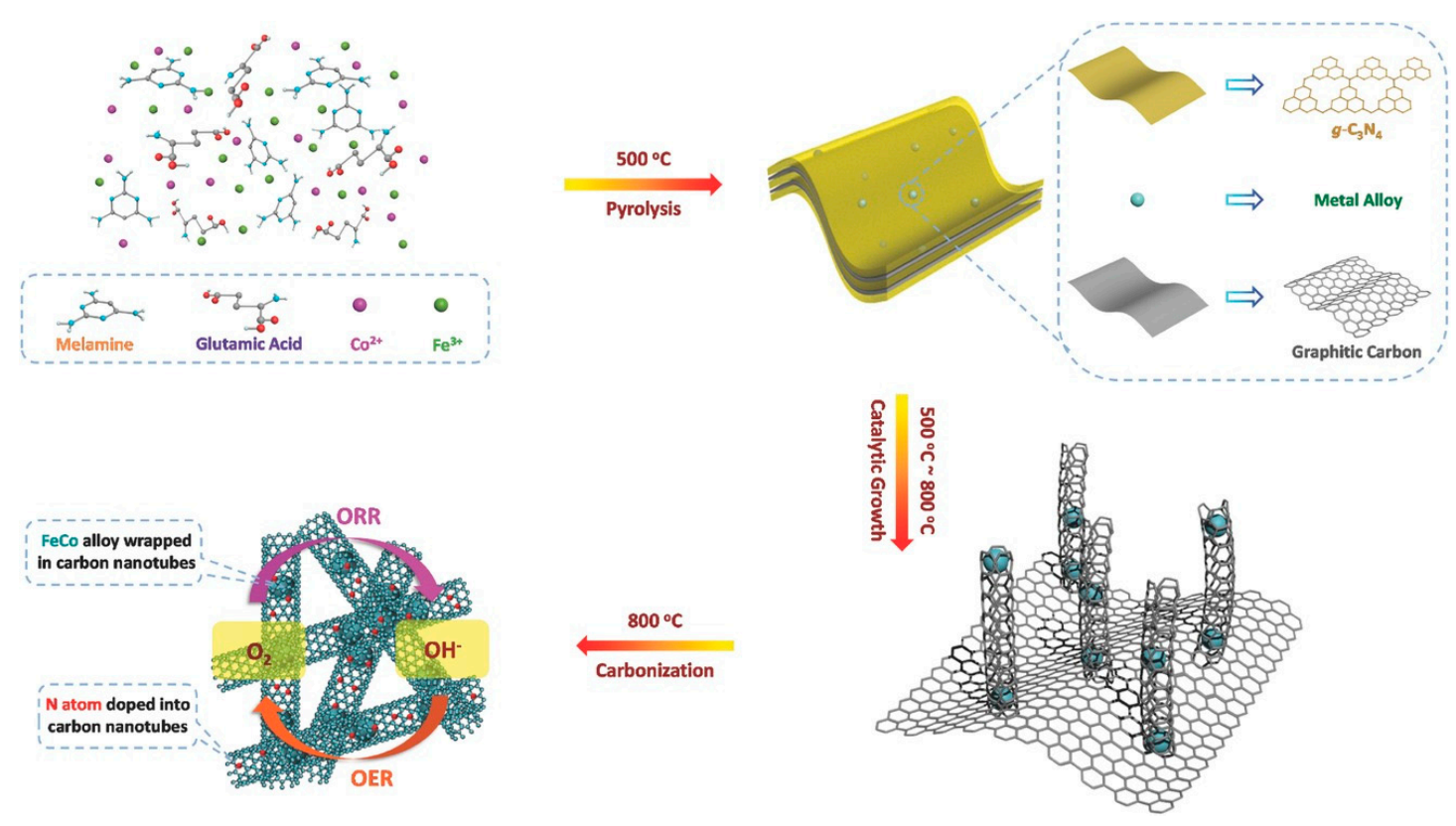

Figure 4. Illustration for the fabrication of N-doped graphitic carbon nanotube (N-GCNT)/FeCo bifunctional hybrids through the temperature-programed carbonization process, reproduced with permission from [42]. Copyright Wiley, 2017.

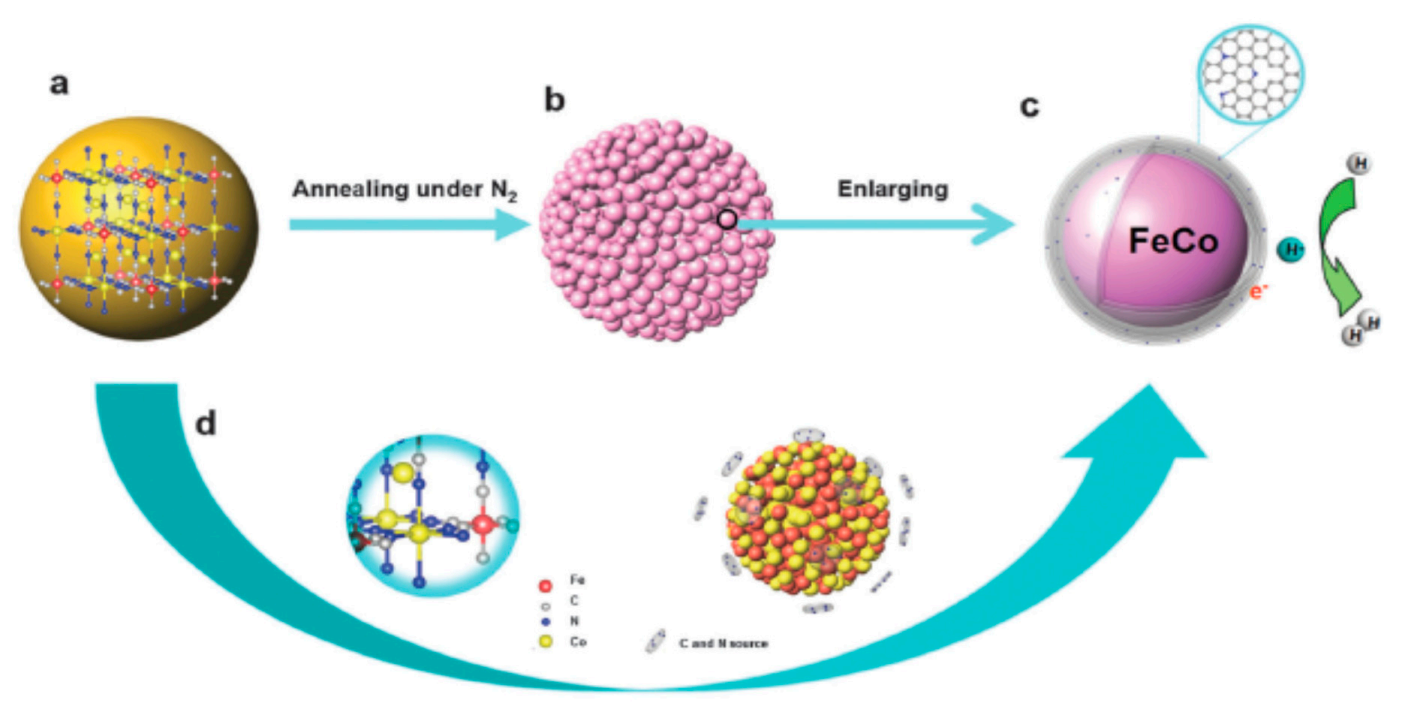

In situ formation

Figure 5. The illustration of synthetic process and model of the FeCo alloys decorated on nitrogen doped graphene layers by annealing corresponding metal-organic frameworks (MOFs), reproduced with permission from [43]. Copyright Royal Society of Chemistry, 2015. 
Metallic/non-metallic heteroatom doping of the hybrids is one of the most efficient approaches to tune the catalyst activity. PBAs precursors were converted to a $(\mathrm{Fe}-\mathrm{Co}) \mathrm{Se}_{2}$ composite by self-assembled strategy and, subsequently, a post-selenization method [45]. $\mathrm{K}_{3}\left[\mathrm{Co}(\mathrm{CN})_{6}\right]$ and $\mathrm{Fe}\left(\mathrm{NO}_{3}\right)_{3}$ are dissolved in the polyvineypirrolydone (PVP)- $\mathrm{HCl}$ solution at $80^{\circ} \mathrm{C}$ to assemble the $\mathrm{Fe}-\mathrm{Co}$ PBAs nanocubes, and are then converted to MOFs-derived bimetallic selenides composites by annealing with selenium powder. TEM images confirm the conversion of the uniform small cubes on the stack nanostructure to stack nanospheres during the post-selenization process. MOFs-derived bimetallic selenides composites with the synthetic bimetal-selenide [46] are more favorable for electrochemical application with the advantages of rapid electron and proton transfer along with dioxygen molecules delivery. Not only does a loose and porous structure offer larger specific surface area and more active sites, but it also expedites the transfer of the electrolyte and the emission of gas bubbles, leading to superior catalytic performance. Co-Fe-P nanotubes were synthesized through a calcination process in air with the Co incorporating with a MIL-88B MOFs (MIL, Materials of Institute Lavoisier) template [47] (Figure 6). The TEM characterizations confirm the hollow structure of Co-Fe-P nanostructure, as well as the fact that the morphology of MOFs-derived materials is strongly connected to the molar ratio of the metal salt precursors following the heterogeneous coordination process in this synthetic case. The positive effect of Co dopant could increase the density of states (DOS) and electrical conductivity and fasten the charge transfer kinetics [48]. The one-dimensional structure of the hollow nanotubes also helps to enhance the structural stability of $\mathrm{Co}-\mathrm{Fe}-\mathrm{P}$, showing excellent durability and long-term stability.
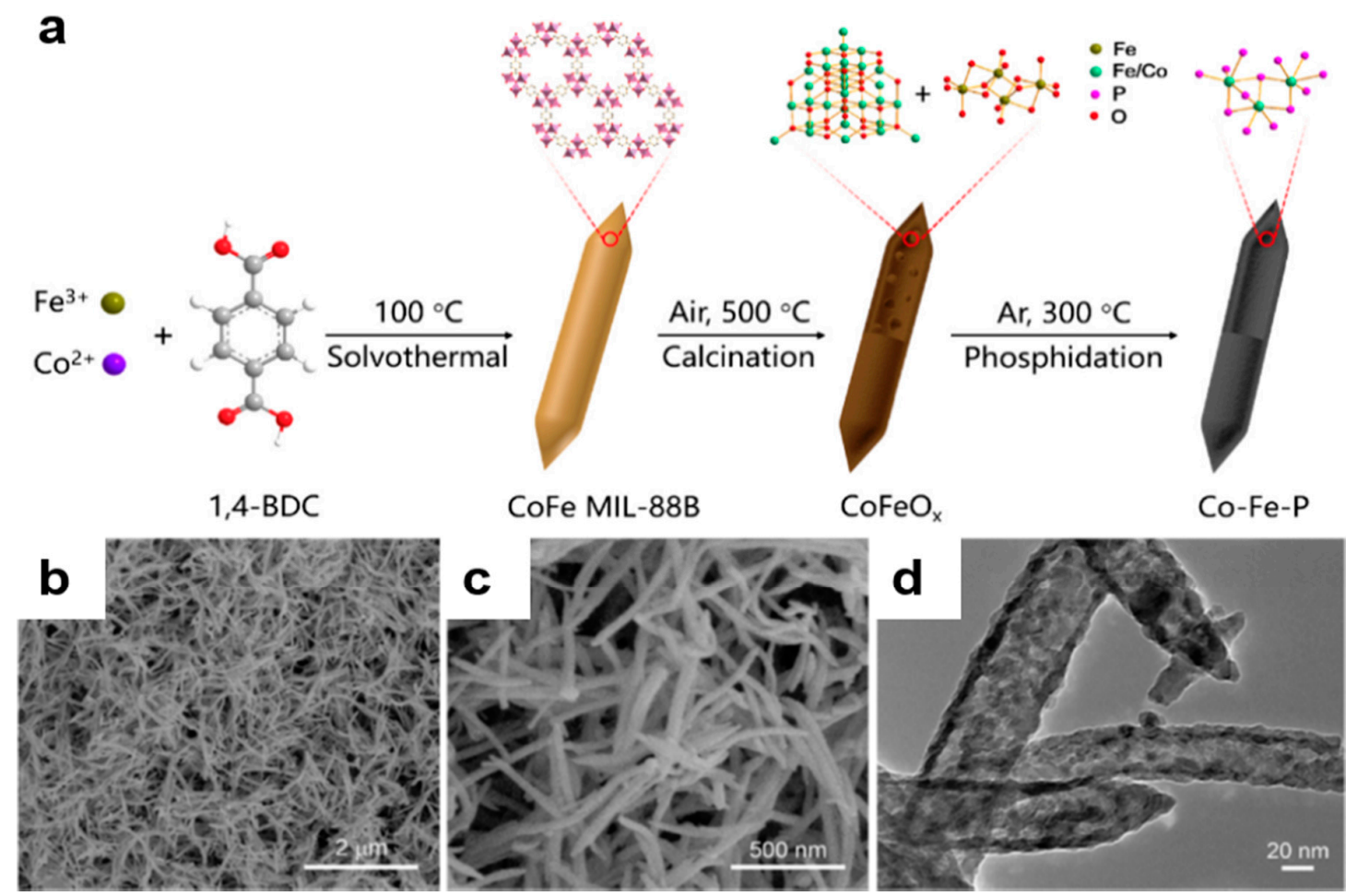

$\mathrm{CoFeO}_{x}$

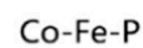

Figure 6. (a) Schematic illustration of the synthesis of Co-Fe-P nanotubes; (b, c) SEM and (d) TEM images of Co-Fe-P nanotubes, reproduced with permission from [47]. Copyright Elsevier, 2019.

Besides using single composition precursors, controllable conversion of two or more MOFs to synthesize desirable functional materials favors the construction of complex MOF-derived nanomaterials from the point of view of both architecture and chemical composition. Lou et al. [49] reported the synthesis process with zeolitic imidazolate framework-67 (ZIF-67, a Co-based MOF) and $\mathrm{Co}-\mathrm{Fe}$ Prussian blue analogue (PBA) (Figure 7a). ZIF-67 nanocube precursors and $\left[\mathrm{Fe}(\mathrm{CN})_{6}\right]^{3-}$ ions proceed a facile anion-exchange reaction with an obvious reaction solution color change from purple to brick red at room temperature and transform into ZIF-67/Co-Fe PBA yolk-shell nanocubes (YSNCs). 
Through a subsequent annealing treatment in air, the YSNCs then further convert to $\mathrm{Co}_{3} \mathrm{O}_{4} / \mathrm{Co}-\mathrm{Fe}$ oxide double-shelled nanoboxes (DSNBs), of slightly concave Co-Fe PBA shell and the inner sharp corner ZIF-67 in each particle (Figure 7b). Constructing nanostructures with specific morphology including solid or hollow nanoparticles, nanowires, nanosheets, and nanotubes, is another approach to change the catalytic properties of the hybrids. The extra active sites embedded on the inner $\mathrm{Co}_{3} \mathrm{O}_{4}$ shells enhance the ECSA of $\mathrm{Co}_{3} \mathrm{O}_{4} / \mathrm{Co}-\mathrm{Fe}$ oxide DSNBs. The structure of PBA nanoshells can be changed by increasing the water fraction and altering the ion exchange reaction rate, which may also enhance the conductivity of the hybrids by the attendance of Fe element in cobalt oxide [50]. Co-Fe PBA hollow structures are also fabricated by employing Co-glycerate nanospheres as the template and precursor synthesis to validate the generality of anion-exchange reaction.

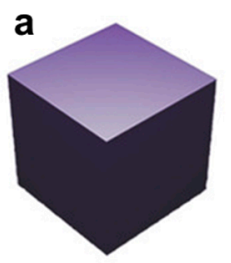

ZIF-67 NCs

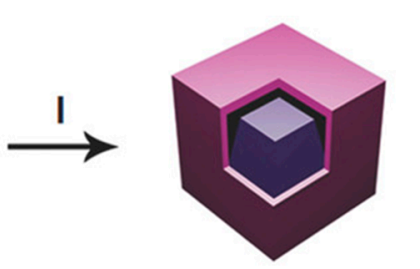

ZIF-67/Co-Fe PBA YSNCs

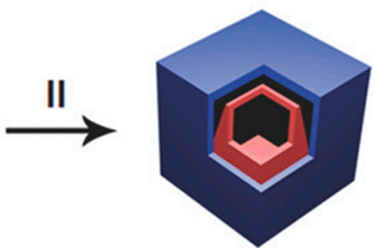

$\mathrm{CO}_{3} \mathrm{O}_{4} / \mathrm{Co}-\mathrm{Fe}$ oxide DSNBs

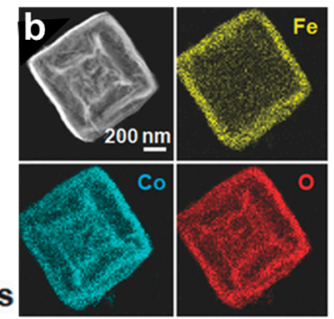

Figure 7. (a) The formation process of $\mathrm{Co}_{3} \mathrm{O}_{4} / \mathrm{Co}-\mathrm{Fe}$ oxide double-shelled nanoboxes (DSNBs): (I) Ion-exchange reaction between ZIF-67 NCs and $\left[\mathrm{Fe}(\mathrm{CN})_{6}\right]^{3-}$ ions to fabricate ZIF-67/Co-Fe PBA yolk-shell nanocubes (YSNCs) and (II) subsequent conversed to the $\mathrm{Co}_{3} \mathrm{O}_{4} / \mathrm{Co}-\mathrm{Fe}$ oxide DSNBs through thermal annealing; (b) TEM and mapping images of the $\mathrm{Co}_{3} \mathrm{O}_{4} / \mathrm{Co}-\mathrm{Fe}-\mathrm{Fe}$ oxide DSNBs, reproduced with permission from [49]. Copyright Wiley, 2018.

The latest development of single-atom electrocatalysts possess optimal activity, stability, and selectivity through the tune strategy of well-defined active centers [51]. MOFs are also used as the substrate to confine Fe-Co dual atom scale sites. The MOF-derived SACs catalysts were synthesized through the pyrolysis of encapsulating $\mathrm{Fe}^{3+}$ in a type of ZIF-8 structure Zn/Co bimetallic MOF [52] (Figure 8). The existence of Fe species may help to modulate the geometric constructions of carbon support, generate $\mathrm{N}$-doped graphene fragments and defects during the pyrolysis, as well as accelerate disintegration of metal-imidazolate-metal linkages. The interior cavities and size enlargement construction through decomposition and graphitization coincide with the Kirkendall effect [28]. All these factors positively impact the mass transport and electronic transfer in ORR.

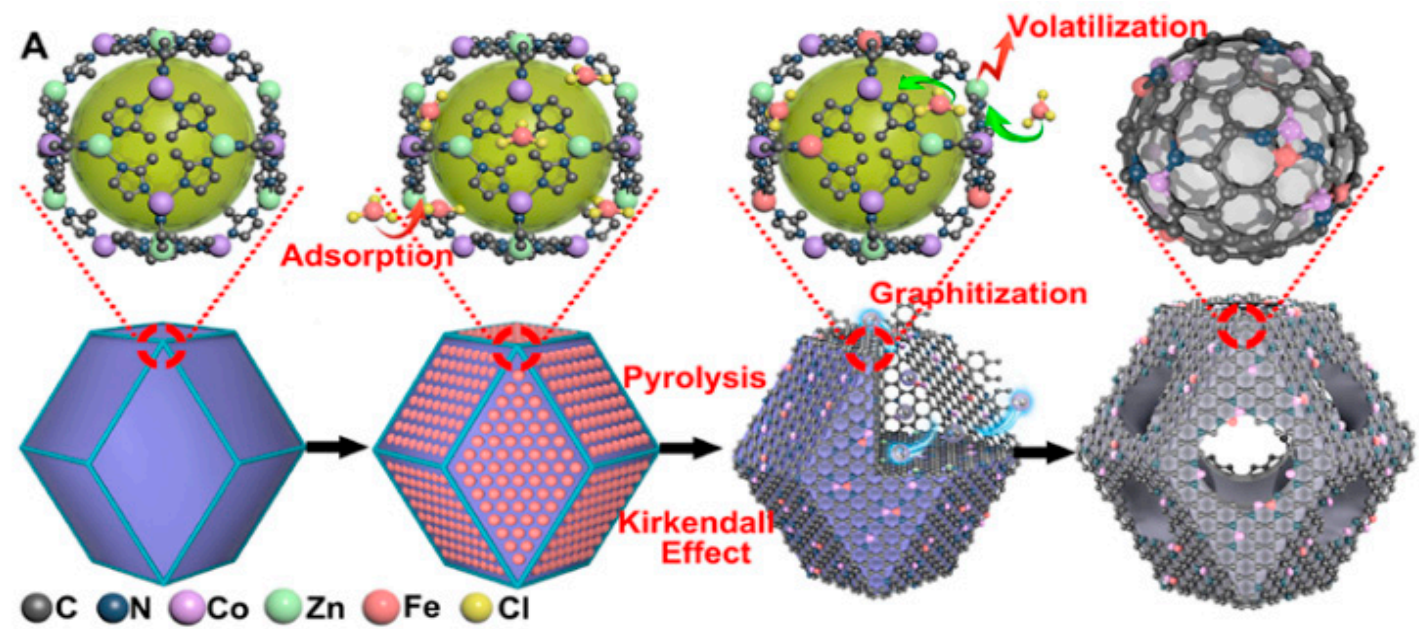

Figure 8. Preparation route of $(\mathrm{Fe}, \mathrm{Co}) / \mathrm{N}-\mathrm{C}$, reproduced with permission from [52]. Copyright American Chemical Society, 2017. 


\section{Applications of Fe/Co Bimetallic Electrocatalysts in Electrochemical Reactions}

Due to the synergistic effects between $\mathrm{Fe}$ and $\mathrm{Co}$ in electrochemical reactions, effective electrocatalysts based on that have been developed for solving energy and environmental crisis. Among the reactions, hydrogen evolution reaction (HER), oxygen evolution reaction (OER), and oxygen reduction reaction (ORR) are most widely concentrated on by researchers, owing to their efficient applications in the energy transfer and conversion process. In the following part, we will summarize the detailed applications and mechanisms of the $\mathrm{Fe} / \mathrm{Co}$ bimetallic catalysts.

\subsection{HER}

Hydrogen is a promising substitute for traditional fossil fuels because of its low pollution and high energy density, while generating hydrogen by electrochemical methods has been thought of as an effective and low-cost way. During this process, developing high-efficiency catalysts for HER is the pivot to decrease the whole cost and enhance the economic value. Electrocatalysts with excellent HER performance can sharply reduce the electronic energy, thus limiting the cost of hydrogen production. The HER process occurs via either Volmer-Heyrovsky mechanism or Volmer-Tafel mechanism depending on different $\mathrm{pH}$ values (Equations (1)-(5)). As $\mathrm{H}^{*}$ is the only intermediate involved in the catalytic process in both acid and alkaline electrolytes, the hydrogen adsorption free energy $\left(\Delta \mathrm{G}_{\mathrm{H}}\right)$ is the key indicator for HER catalysts. In the typical volcano plot [53] (Figure 9a), $\mathrm{Pt}$ locates near the top, behaving with the best HER activity. However, the non-precious metals Fe and Co and their derivatives also perform well, even exceeding $\mathrm{Pt}$ in activity and reduction of cost.

$$
\begin{gathered}
\mathrm{H}^{+}+\mathrm{e}^{-} \rightarrow \mathrm{H}^{*} \text { (Volmer reaction in acid solution) } \\
\mathrm{H}_{2} \mathrm{O}+\mathrm{e}^{-} \rightarrow \mathrm{H}^{*}+\mathrm{OH}^{-} \text {(Volmer reaction in alkaline solution) } \\
\mathrm{H}^{*}+\mathrm{H}^{*} \rightarrow \mathrm{H}_{2} \text { (Tafel reaction) } \\
\mathrm{H}^{+}+\mathrm{H}^{*}+\mathrm{e}^{-} \rightarrow \mathrm{H}_{2} \text { (Heyrovsky reaction in acid solution) } \\
\mathrm{H}_{2} \mathrm{O}+\mathrm{H}^{*}+\mathrm{e}^{-} \rightarrow \mathrm{H}_{2}+\mathrm{OH}^{-} \text {(Heyrovsky reaction in alkaline solution) }
\end{gathered}
$$

\subsubsection{Bimetallic Alloy-Based Electrocatalysts}

Among the composites involving $\mathrm{Fe}$ and $\mathrm{Co}$, alloys can reflect the synergistic effects of the two elements most directly. However, the early binary Fe-Co alloy nanoparticles exhibit poor HER activity. Ahmed et al. [4] microemulsion-based synthesized spherical, uniform, and highly monodisperse nanoparticles, including $\mathrm{Fe}_{75} \mathrm{Co}_{25}, \mathrm{Fe}_{67} \mathrm{Co}_{33}, \mathrm{Fe}_{50} \mathrm{Co}_{50}$, and $\mathrm{Fe}_{33} \mathrm{Co}_{67}$ with average sizes of 20, 25, 10 , and $40 \mathrm{~nm}$, respectively. Electrocatalytic tests indicate that $\mathrm{Fe}_{33} \mathrm{Co}_{67}$ nanoparticles show better performance compared with $\mathrm{Fe}_{67} \mathrm{Co}_{33}$ and $\mathrm{Fe}_{75} \mathrm{Co}_{25}$ nanoparticles, whereas the HER performance is still unsatisfactory. To improve the HER activities of Fe-Co alloy-based materials in wide $\mathrm{pH}$ ranges, an N-doped carbon shell is introduced to the catalysts as a substrate. An N-doped carbon shell can not only provide abundant adsorption sites for $\mathrm{H}^{*}$, but also prevents the aggregation and combination of the alloy nanoparticles and exposes a larger active area. For HER in acid solution, Yang et al. [43] reported a facile process to fabricate Fe-Co alloy nanoparticles that are encapsulated in high-level nitrogen content-doped ( 8.2 atom\%) graphene layers by annealing MOF precursors at $600{ }^{\circ} \mathrm{C}$ in $\mathrm{N}_{2}$ directly. The HER performance of the material is highly improved compared with the former $\mathrm{Fe}_{33} \mathrm{Co}_{67}$, showing a low onset potential $(88 \mathrm{mV})$ and achieving $10 \mathrm{~mA} \mathrm{~cm}^{-2}$ at $262 \mathrm{mV}$ in $0.5 \mathrm{M}$ $\mathrm{H}_{2} \mathrm{SO}_{4}$ (Figure 9b). This design employs Prussian blue analogues (PBAs) and transition metals as precursors, obtaining an ideal electrocatalyst with outstanding stability for HER owing to protection of the N-doped graphene shell. According to the density functional theory calculation (DFT) (Figure 9c), the active sites for HER are still mainly the nitrogen atoms doped in carbon matrix as the metallic alloy is almost encapsulated in graphene layers entirely. Nitrogen doping can improve the activity not only 
by providing adsorption sites for $\mathrm{H}^{*}$, but also by decreasing $\Delta \mathrm{G}_{\mathrm{H}}$ for HER in acid. The alloy core and the nitrogen-doped graphitic shell can generate the synergism of metal components and carbon support, which could facilitate HER. $\Delta \mathrm{G}_{\mathrm{H}}$ of pure metal models $\left(\mathrm{Co}_{4}\right.$ and $\left.\mathrm{Co}_{2} \mathrm{Fe}_{2}\right)$ are also calculated in this work. Both models show relatively negative $\Delta \mathrm{G}_{\mathrm{H}}$, which is unfavorable for the desorption step. However, $\Delta \mathrm{G}_{\mathrm{H}}$ of the $\mathrm{Co}_{2} \mathrm{Fe}_{2}$ is closer to zero than pure $\mathrm{Co}$, indicating the alloy performs better than the pure metal, showing the synergistic effect between the metals. Similar alloy materials are also reported and applied in alkaline solution for HER. Li et al. [37] showed a novel 3D hierarchically porous flower-like structure of tiny $\mathrm{FeCo@NC} \mathrm{ultrathin} \mathrm{with} \mathrm{N}$-doped carbon nanosheets core-shell groups dispersed on the surfaces. The reported favorable $\mathrm{Fe}_{0.5} \mathrm{Co}_{0.5} @ \mathrm{NC} / \mathrm{NCNS}-800$ sample shows a high activity for catalyzing HER in $1.0 \mathrm{M}$ potassium hydroxide $(\mathrm{KOH})$, with an onset potential of $-63 \mathrm{mV}$ and a low overpotential of $150 \mathrm{mV}$ to achieve $10 \mathrm{~mA} \mathrm{~cm}^{-2}$. In order to test where the activity for HER originates from, pure $\mathrm{Fe}_{0.5} \mathrm{Co}_{0.5}$ (reduced by $\mathrm{NH}_{3}$ ) and acid- $\mathrm{Fe}_{0.5} \mathrm{Co}_{0.5} @ \mathrm{NC} / \mathrm{NCNS}-800$ are synthesized as comparisons. Catalytic activities of both the comparisons obviously decay, demonstrating that only perfect FeCo@NC core-shell structure could effectively catalyze the HER process in alkaline electrolyte.
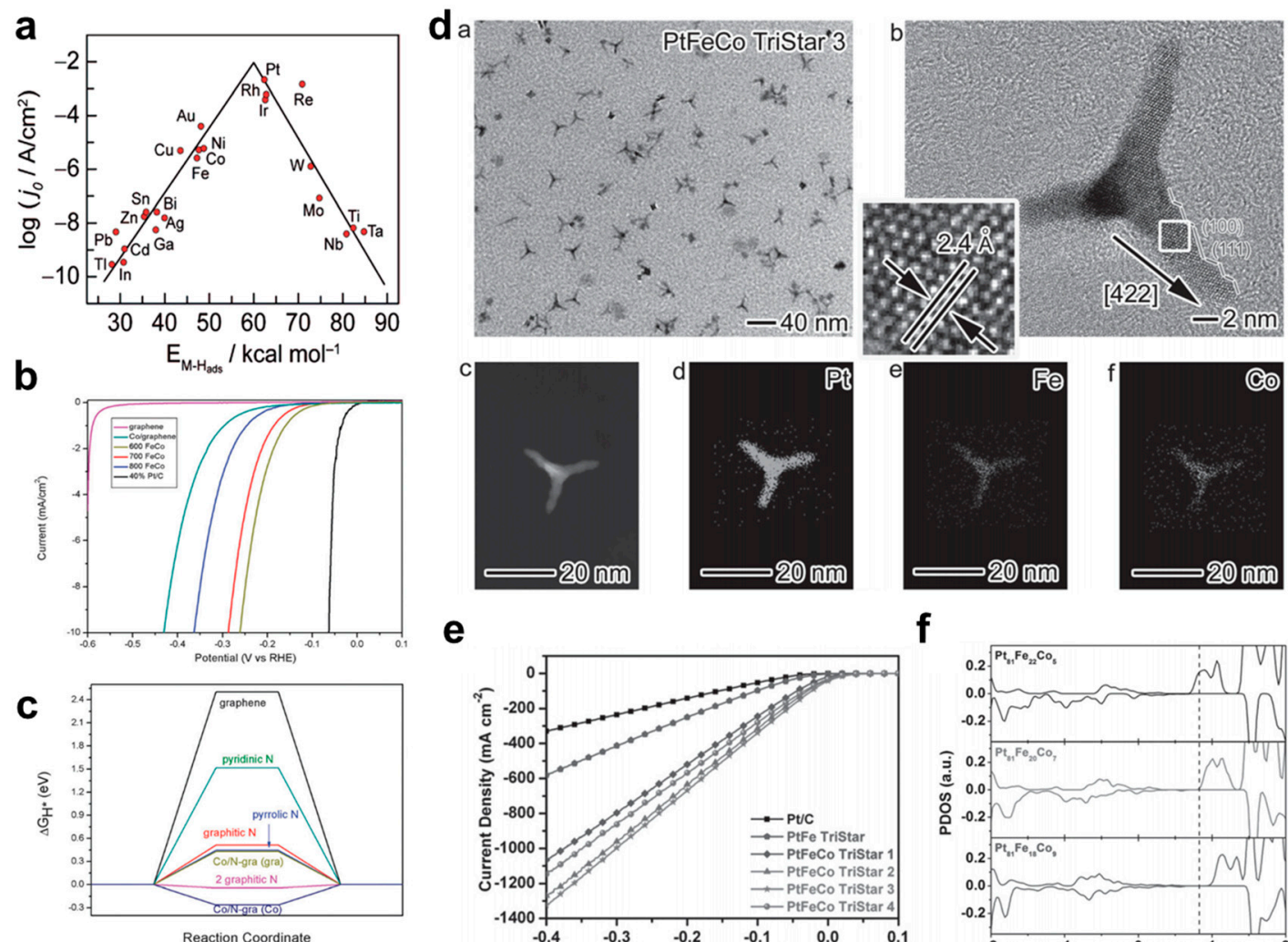

e

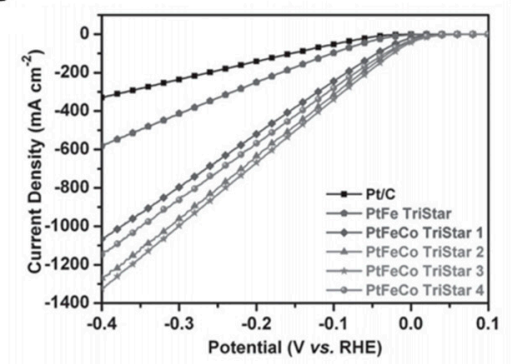

f

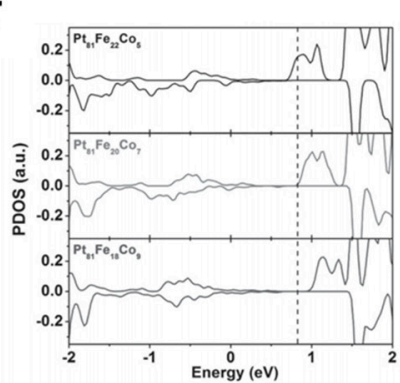

Figure 9. (a) The typical volcano curve for the hydrogen evolution reaction (HER) performance of the metal materials in acid solution, reproduced with permission from [53]. Copyright American Chemical Society, 2010. (b) The polarization curves of FeCo alloy samples of different temperatures; (c) calculated $\Delta \mathrm{G}_{\mathrm{H}}{ }^{*}$ diagram of some models; the words in the brackets differ from the $\mathrm{H}^{*}$ adsorbed on the graphene side or $\mathrm{Co}_{4}$ side, reproduced with permission from [43]. Copyright Royal Society of Chemistry, 2015. (d) TEM, HRTEM, and STEM mapping images of $\mathrm{Pt}_{81} \mathrm{Fe}_{28} \mathrm{Co}_{10}$ nanostructures in a TriStar shape; (e) Polarization curves for Pt-based alloy TriStar nanostructures in different chemical compositions compared with $\mathrm{Pt} / \mathrm{C}$ at the same total metal loading weights in $0.5 \mathrm{M} \mathrm{H}_{2} \mathrm{SO}_{4}$ (aq) electrolyte; (f) calculated projected density of states (PDOS) diagrams for the $d$ orbitals of Pt atoms in three types of PtFeCo lattices in neutral condition, reproduced with permission from [54]. Copyright Wiley, 2016. 
Apart from coating the alloy with carbon shells, there are other methods to decorate the alloy, thereby exhibiting favorable activities in different $\mathrm{pH}$. By combining non-noble metals like Fe and Co with noble metal like Pt, trimetallic tristar nanostructures were reported by Du et al. [54], and they tuned electronic and surface structures for enhanced electrocatalytic hydrogen evolution in acid. Different from the former ones, the activity for HER of the PtFeCo comes mainly from metal Pt. However, each type of transition metal would have a specific function in influencing the Pt-based alloy material behaviors for HER. Fe can induce more intense charge polarization on $\mathrm{Pt}$ compared with $\mathrm{Co}$, which coincides with the experimental results of PtFe NP exhibiting higher HER activity. However, when an Fe atom in the $\mathrm{Pt}_{81} \mathrm{Fe}_{27}$ lattice is replaced by $\mathrm{Co}$, the charge accumulation on the $\mathrm{Pt}$ atoms close to the Co would increase, generating highly active sites. As a result, it is necessary to incorporate abundant Co atoms into the PtFe lattice to form trimetallic alloy. In addition, by calculating the projected density of states (PDOS) of $\mathrm{Pt} d$ orbitals, the PDOS distribution gradually shifts along with the increase of Co content. By controlling the Co:Fe ratio, the d-band center is adjusted to an optimal distance to the Fermi level, obtaining the best HER activity (Figure 9d-f). Electrochemical methods are also widely applied to alloy materials for catalyzing HER in alkaline condition. Müller et al. [55] prepared $\mathrm{Fe}_{60} \mathrm{Co}_{20} \mathrm{Si}_{10} \mathrm{~B}_{10}$ alloy for HER in a rapid solidification process using a melt spinning device. The alloy with a composition of $\mathrm{Fe}_{0.75} \mathrm{Co}_{0.25}$ is suggested to be the active surface species. Liu et al. [56] carried out a one-step electro-reductive deposition method to form a Fe-Co composite film above carbon fiber paper in solution. The obtained Fe-Co composite films exhibit efficient electrocatalytic performance and durability for HER, reaching $10 \mathrm{~mA} \mathrm{~cm}^{-2}$ at a low overpotential of $163 \mathrm{mV}$ in $1.0 \mathrm{M} \mathrm{KOH}$.

\subsubsection{Bimetal Phosphide Electrocatalysts}

Since the simple alloys lack sufficient active sites for HER and show poor performance, several classes of transition metal derivatives have been developed as candidates to replace the rare Pt. For HER, transition metal-based phosphides (TMPs) have exhibited activities superior to other types of compounds. By both experimental and theoretical methods for HER in acid environment, Kibsgaard et al. [8] designed an enhanced transition metal phosphide electrocatalyst. By using DFT calculation, the $\Delta \mathrm{G}_{\mathrm{H}}$ is consistent with a volcano trend and is located within a narrow range at the top of the volcano plot (Figure 10a,b). The results show that $\mathrm{CoP}$ and $\mathrm{FeP}$ exhibit hydrogen adsorption free energies in each side of the optimum $\Delta \mathrm{G}_{\mathrm{H}}$ value. $A \mathrm{Fe}_{0.5} \mathrm{Co}_{0.5} \mathrm{P}$ with a $\Delta \mathrm{G}_{\mathrm{H}}$ value that is closer to the optimum value than either the value of $\mathrm{CoP}$ or FeP is designed. The high efficiency of such a structure is also confirmed by experimental methods. Regarding applications of TMPs in wider $\mathrm{pH}$ ranges, Zhang et al. [57] found that the different doping level of Fe in CoP has various effects on catalytic properties in different conditions. By adjusting the ratio of precursors, hybrids denoted as $\mathrm{CoP} / \mathrm{CNT}$ or $\mathrm{Co}_{1-\mathrm{x}} \mathrm{Fe}_{\mathrm{x}} \mathrm{P} / \mathrm{CNT}$ (with $\mathrm{x}=0.1,0.2,0.3,0.4$, and 0.5 ) are synthesized by a simple two-step device. The catalytic activity of $\mathrm{Co}_{1-x} \mathrm{Fe}_{x} \mathrm{P} / \mathrm{CNT}$ for HER improves following the increase of Fe mixing ratio from $\mathrm{x}=0$ to the optimal $\mathrm{x}=0.4$. The $\mathrm{Co}_{0.6} \mathrm{Fe}_{0.4} \mathrm{P} / \mathrm{CNT}$ electrocatalyst can afford a current density of $10 \mathrm{~mA} \mathrm{~cm}^{-2}$ at an ultra-low overpotential of $67 \mathrm{mV}$. In alkaline electrolyte, the $\mathrm{Co}_{1-x} \mathrm{Fe}_{x} \mathrm{P} / \mathrm{CNT}$ hybrid also shows excellent HER activities; however, the trend of performance catalyzing HER along with the Fe mixing ratio is different from that in acidic solution. With higher content of Fe, the hybrids exhibit worse catalytic performance. In acid electrolyte, the best activity is denoted by Fe-free CoP/CNT electrode with only $76 \mathrm{mV}$ to afford $10 \mathrm{~mA} \mathrm{~cm}^{-2}$. Alloyed $\mathrm{Fe}-\mathrm{Co}$ mono-phosphide exhibits a medial $\Delta \mathrm{G}_{\mathrm{H}}$ between that of $\mathrm{CoP}$ and $\mathrm{FeP}$, leading to an optimized hydrogen binding. Therefore, the better HER performance of the obtained $\mathrm{Co}_{1-x} \mathrm{Fe}_{x} \mathrm{P} / \mathrm{CNT}$ catalysts with increased Fe content can be mainly ascribed to the better hydrogen adsorption thermodynamic on the surface of $\mathrm{Co}_{1-x} \mathrm{Fe}_{x} \mathrm{P}$ catalyst, which is induced by Fe-doping. However, in an alkaline condition, the negatively charged $\mathrm{P}$ sites play the role of the proton acceptor centers to facilitate the generation of metal hydrides on the proximate metal centers. Since the electron negativity of $\mathrm{Fe}$ atom is lower than that of $\mathrm{Co}$, more positive charges on metal sites are expected with increased Fe incorporation. The larger positive charges will induce stronger adsorption of hydroxyl on metal centers, resulting in less accessibility for proton adsorption 
to form metal hydrides. These factors can explain the opposite trend in alkaline electrolyte induced by Fe-doping.
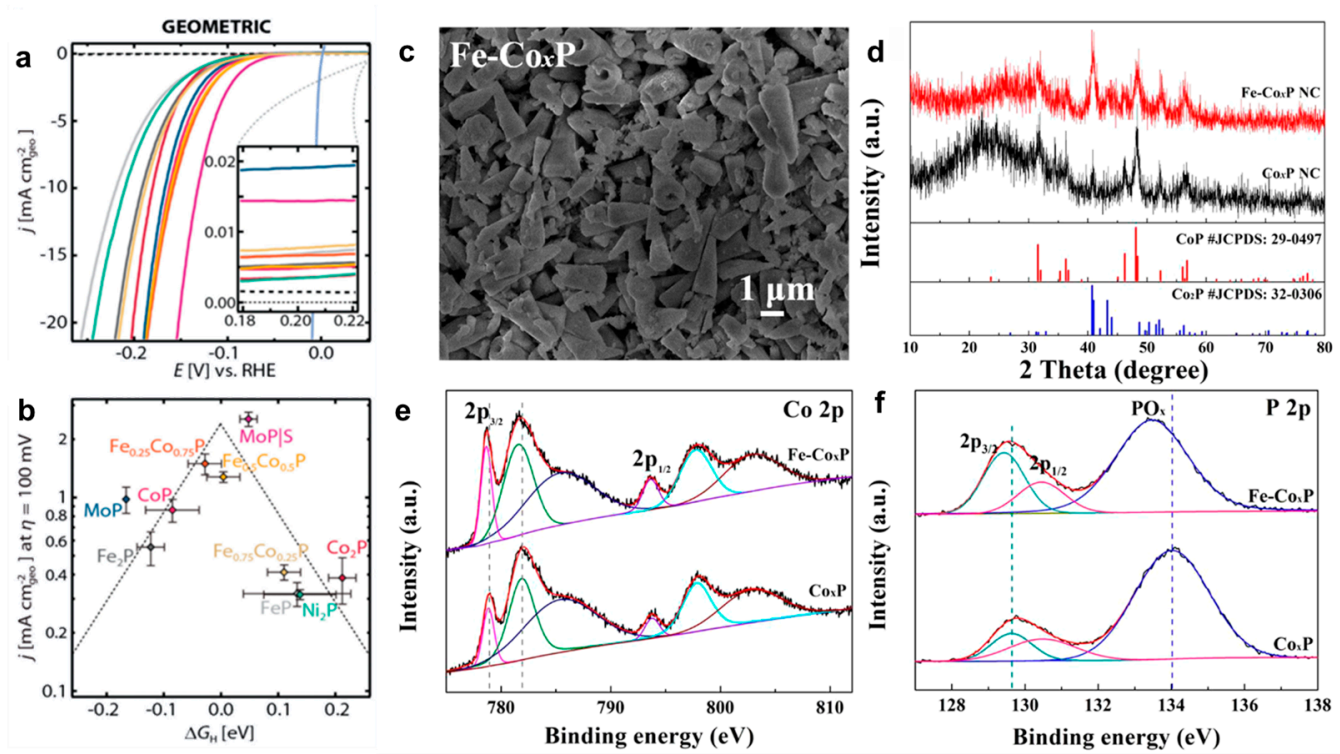

Figure 10. (a) The polarization curves per geometric area for transition metal phosphide electrodes. The inset figure is a zoom-in on a potential region. The polarization curve of Pt nanoparticles (NPs) is displayed for comparison; (b) activity volcano plot for HER performance, showing the geometric current density from (a) at $\eta=100 \mathrm{mV}$ as a function of hydrogen adsorption free energy $\left(\Delta \mathrm{G}_{\mathrm{H}}\right)$, reproduced with permission from [8]. Copyright Royal Society of Chemistry, 2015. (c) SEM image of Fe-doped $\mathrm{Co}_{x} \mathrm{P}$ nanocones; (d) XRD patterns of $\mathrm{Co}_{x} \mathrm{P}$ and Fe-doped $\mathrm{Co}_{x} \mathrm{P}$ nanocones; XPS spectra of (e) Co $2 \mathrm{p}$ and (f) $\mathrm{P} 2 \mathrm{p}$ for $\mathrm{Co}_{x} \mathrm{P}$ and Fe-doped $\mathrm{Co}_{x} \mathrm{P}$ nanocones, reproduced with permission from [58]. Copyright American Chemical Society, 2018.

Compared with $\mathrm{FeP}$, the $\mathrm{CoP}$ crystals are easier to form when post-processing the bimetal precursors like MOF, Prussian blue analogues, and metal hydroxides. The obtained catalysts show outstanding HER activities in various electrolytes. For example, Guo et al. [58] reported PBAs nanocones and their transition into $\mathrm{Fe}$-doped $\mathrm{Co}_{x} \mathrm{P}$ nanocones by intercalation synthesis. The $\mathrm{Fe}-\mathrm{Co}$ PBAs nanocones are prepared by an intercalation strategy, employing layer structured $\alpha-\mathrm{Co}(\mathrm{OH})_{2} \mathrm{NCs}$ as self-sacrificed templates. Electrochemical analysis indicates that incorporating Fe can effectively improve the HER activities in acid solution because of the increase of electrochemical surface area (ECSA) and more suitable free energy of hydrogen adsorption on Co-centered sites (Figure 10c-f). For the alkaline electrolyte, Li et al. [59] used cobalt- and iron-containing metal-organic frameworks (MOF, ZIF-67@MIL-88B) as precursors followed by a phosphorization process, thus obtaining Fe-doped porous cobalt phosphide polyhedron $\left(\mathrm{Co}_{0.68} \mathrm{Fe}_{0.32} \mathrm{P}\right)$. The morphology of the polyhedron structure remains after the phosphorization process but exhibits high porosity. As-prepared porous $\mathrm{Co}_{0.68} \mathrm{Fe}_{0.32} \mathrm{P}$ shows a small onset overpotential of $84 \mathrm{mV}$ in $1.0 \mathrm{M} \mathrm{KOH}$ and an $\eta_{10}$ (the overpotential to achieve the current density of $10 \mathrm{~mA} \mathrm{~cm}^{-2}$ ) of $116 \mathrm{mV}$. When doping Fe into the CoP, the HER performance will increase significantly. With its weaker electronegativity, Fe doping results in much weaker binding between $\mathrm{Co}$ and $\mathrm{P}$, leading to the formation of low oxidation state $\mathrm{Co}$ and elemental $\mathrm{Co}$. The unsaturated Co will further change the charge-density distribution on the surface of the electrocatalyst, giving rise to different $\mathrm{H}$ adsorption energies. Prussian blue analogues are also a serious of precursors for $\mathrm{Fe}-\mathrm{CoP}$ hybrids. Similarly, Cao et al. [60] studied an easy and practical approach to obtain a bimetal catalyst by directly synthesizing a Co-Fe Prussian blue analogue on a 3D porous conductive support (nickel foam), which is then phosphorized into Fe-doped CoP. The Fe-CoP/NF electrocatalyst exhibits efficient electrocatalytic HER activities with a very low overpotential of $78 \mathrm{mV}$ to achieve the current density of $10 \mathrm{~mA} \mathrm{~cm}^{-2}$ in $1.0 \mathrm{M} \mathrm{KOH}$. 
On the contrary, Co incorporating FeP nanotubes by a metal-organic frameworks templating strategy was also proposed by Chen et al. [47] for efficient hydrogen evolution. The Co-Fe-P nanotubes achieve excellent HER catalytic performance within a wide $\mathrm{pH}$ range, reaching $10 \mathrm{~mA} \mathrm{~cm}{ }^{-2}$ at low overpotentials of 86,138 , and $66 \mathrm{mV}$ in $1 \mathrm{M} \mathrm{KOH}, 1 \mathrm{M}$ phosphate buffer solution (PBS), and $0.5 \mathrm{M}$ $\mathrm{H}_{2} \mathrm{SO}_{4}$, respectively. Based on DFT calculations, Co incorporation significantly increases the density of states (DOS) for $d$-orbital near Fermi level, resulting in higher electrocatalytic activity. Different from the discussed situations, Kim et al. [61] fabricated a 3D porous Co-Fe-P framework utilizing an electrodeposition method. The optimal electrodeposited layers have an amorphous structure while owning excellent HER performance $\left(73 \mathrm{mV}\right.$ at $\left.10 \mathrm{~mA} \mathrm{~cm}^{-2}\right)$ in alkaline solution. Except for the synthesis of metal phosphides, P was also applied for modification. Kuo et al. [62] improved HER activity of cobalt-doped $\mathrm{FeS}_{2}$ electrocatalysts by surface phosphorization. The $\mathrm{P} / \mathrm{Co}-\mathrm{FeS}_{2}$ nanocomposites grown on the carbon fiber paper substrate achieve geometric current densities of $10 \mathrm{~mA} \mathrm{~cm}^{-2}$ at much lower voltage of $-63 \mathrm{mV}$ compared to that of $\mathrm{Co}-\mathrm{FeS}_{2}$ on the substrate $(-102 \mathrm{mV})$.

\subsection{OER}

Oxygen evolution reaction (OER) is a crucial part in water splitting and recharging metal-air batteries, whereas it is limited by sluggish kinetics. The mechanisms and pathways for OER are more complicated than those for HER. Up to this point, Ir/Ru-based metal materials have been regarded as state-of-the-art electrocatalysts to burst through the kinetic barriers, but their high expense and rare resources hinder their wider applications. To overcome the difficulties, transition metals and their derivatives have been developed as candidates to replace the noble metals. It is generally acknowledged that the OER includes the following steps, where the symbol ${ }^{* \prime \prime}$ represents the active sites.

$$
\begin{aligned}
*+\mathrm{OH}^{-} & \rightarrow \mathrm{HO}^{*}+\mathrm{e}^{-} \\
\mathrm{HO}^{*}+\mathrm{OH}^{-} & \rightarrow \mathrm{H}_{2} \mathrm{O}+\mathrm{O}^{*}+\mathrm{e}^{-} \\
\mathrm{O}^{*}+\mathrm{OH}^{-} & \rightarrow \mathrm{HOO}^{*}+\mathrm{e}^{-} \\
\mathrm{HOO}^{*}+\mathrm{OH}^{-} & \rightarrow \mathrm{O}_{2}^{*}+\mathrm{H}_{2} \mathrm{O}+\mathrm{e}^{-} \\
\mathrm{O}_{2} & \rightarrow \mathrm{O}_{2}{ }^{*}
\end{aligned}
$$

\subsubsection{Bimetallic Alloy-Based Electrocatalysts}

Fe-Co bimetal electrocatalysts exhibit outstanding properties for OER even exceeding Ir/Ru-based materials due to their synergistic effects. To investigate the intrinsic mechanisms, the Fe-Co alloy materials are firstly summarized and analyzed. As we know, the nitrogen doped with metal center is generally regarded as active for OER. For instance, Wu et al. [27] reported a facile preparation of FeCo@NC core-shell nanospheres with graphene substrate displaying outstanding OER performance (Figure 11a,b). The process for fabricating the $\mathrm{FeCo} / \mathrm{NC}$ electrocatalysts is a facile one-step pyrolysis of graphitic carbon nitride and acetylacetonates. Calculated by the first-principles calculation, the nitrogen doping can activate the adjacent carbon for the electro reactions by modifying the spin status, charge density, and energy bandgap. The encapsulated bimetal alloy nanoparticles in the material will more deeply modulate the electronic environment of the $\mathrm{M}-\mathrm{N}-\mathrm{C}$ sites and enhance the free-energy of adsorption of the oxygen-containing reactants onto the surface of the catalyst. When pyrolyzing carbon source and Co containing materials, carbon nanotubes are easy to generate due to the catalytic effect of Co. As a result, the hierarchical structures consisting of alloy nanoparticles, carbon nanotubes, and carbon sheets are widely synthesized. Liu et al. [63] also reported a two-step fabrication of CoFe alloy nanoparticles supported by nitrogen-doped carbon nanosheets/carbon nanotubes for OER. The CoFe-N-CN/CNTs hybrid material achieves $10 \mathrm{~mA} \mathrm{~cm}^{-2}$ at a small overpotential of $285 \mathrm{mV}$ and shows a low Tafel slope of $51.09 \mathrm{mV} \mathrm{dec}^{-1}$. It is hypothesized that the synergistic effect from the bimetal alloy and nitrogen dopant may be due to the formation of $\mathrm{M}-\mathrm{N}_{\mathrm{x}}$ active sites. To further prove 
the mechanism, the OER linear sweep voltammetry (LSV) curves are obtained in alkaline solution with and without $\mathrm{SCN}^{-}$. As a probe, $\mathrm{SCN}^{-}$can poison $\mathrm{M}-\mathrm{N}_{\mathrm{x}}$ sites through combining strongly with the $\mathrm{M}-\mathrm{N}_{\mathrm{x}}$ active sites, thus it can be utilized to investigate the function of the metal-centered sites. The OER performance of the $\mathrm{CoFe}-\mathrm{N}-\mathrm{CN} / \mathrm{CNTs}$ exhibits a negative shift after the introduction of $\mathrm{SCN}^{-}$ions. The decreased activity can be ascribed to the fact that the $\mathrm{CoFe}-\mathrm{N}-\mathrm{CN} / \mathrm{CNTs}$ containing $\mathrm{M}-\mathrm{N}_{\mathrm{x}}$ sites play a critical role in the improvement of the OER activity.
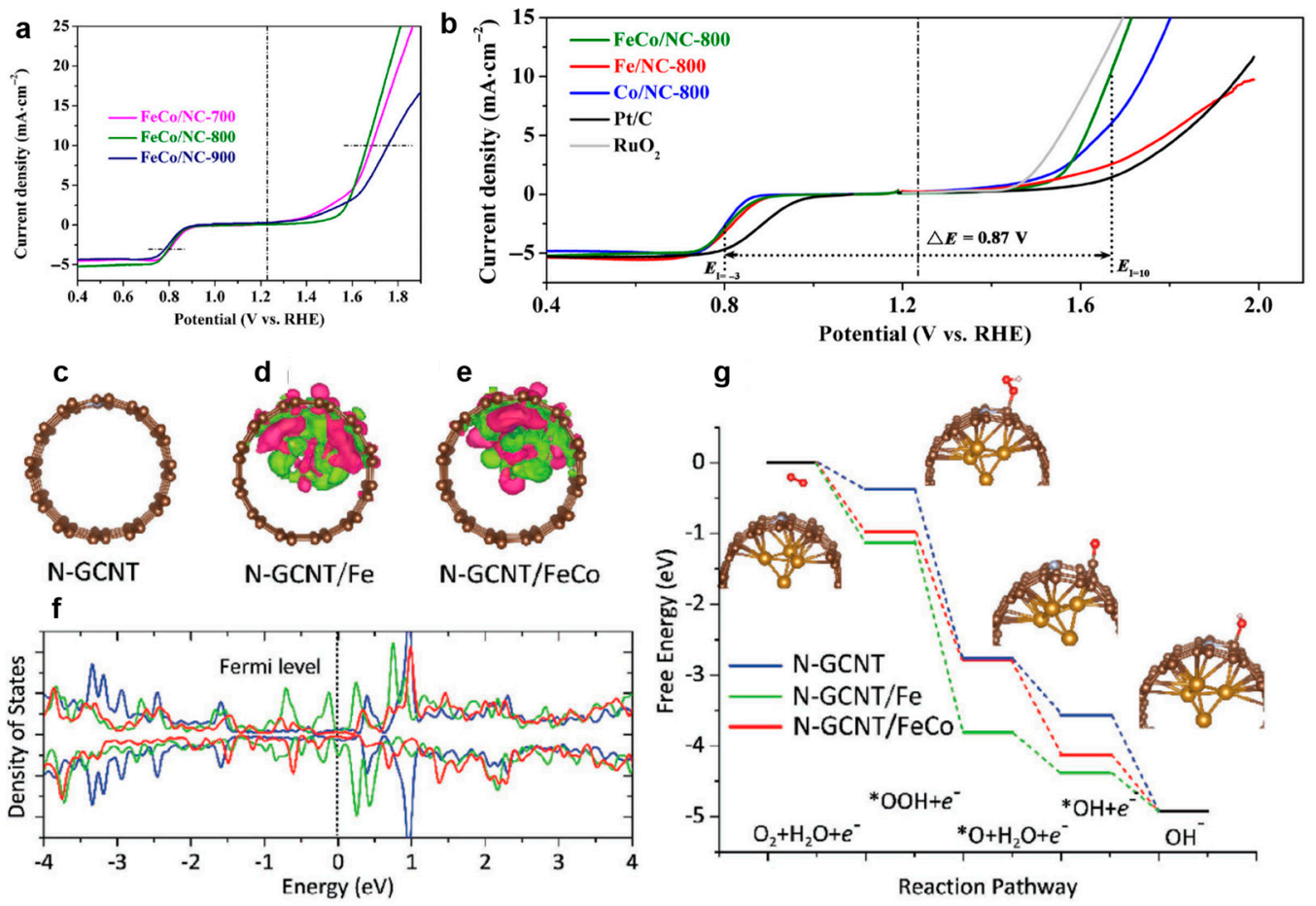

Figure 11. (a) OER and ORR activities of FeCo/NC-700, FeCo/NC-800, and FeCo/NC-900 in $0.1 \mathrm{M} \mathrm{KOH}$ solution from 0.4 to $1.9 \mathrm{~V}$; (b) LSV curves of Fe/NC-800, Co/NC-800, $\mathrm{FeCo} / \mathrm{NC}-800, \mathrm{Pt} / \mathrm{C}$, and $\mathrm{RuO}_{2}$ samples from 0.4 to $2.0 \mathrm{~V}$, reproduced with permission from [27]. Copyright Springer Nature, 2017. (c) The optimized morphology of bare N-GCNT. (d) The isosurface $\left(0.1 \mathrm{e} \AA^{-3}\right)$ of charge density variation in N-GCNT/Fe. Green area represents decrease in charge density $(\Delta \rho<0)$ and purple area represents increase in charge density $(\Delta \rho>0)$. (e) The isosurface of charge density variation in N-GCNT/FeCo. (f) The simulated density of states for the p orbitals of the active $\mathrm{C}$ atoms in N-GCNT, N-GCNT/Fe, and N-GCNT/FeCo. (g) The free-energy plot of the ${ }^{*} \mathrm{OOH},{ }^{*} \mathrm{O},{ }^{*} \mathrm{OH}$ intermediates in the typical $4 \mathrm{e}^{-}$ reaction-pathway for ORR catalyzed by N-GCNT, N-GCNT/Fe, and N-GCNT/FeCo, reproduced with permission from [42]. Copyright Wiley, 2017.

Similar testimony exists in another work by Liu et al. [64], who developed a bamboo-like hierarchical structure consisting of CoFe alloy nanoparticles embedded in $\mathrm{N}$-doped carbon nanotubes supported by reduced graphene oxide, presenting favorable ORR/OER activity and promising application in Zn-air batteries. In this work, in situ X-ray adsorption spectroscopy is applied to reveal the detailed origin of the CoFe alloy. In particular, the K-edge X-ray absorption near edge structure (XANES) spectrum of Fe and Co shows minor variation with larger potential, suggesting the valence states of Fe and Co do not change, evidently. The corresponding FT-EXAFS data demonstrate that the length of $\mathrm{Fe}-\mathrm{Fe}$ bonds experience a variation of extension and then shorten with the increase of potential, suggesting that the ORR process at lower potentials primarily happens on the Fe species. On the contrary, the Co-Co bond length sees a process of first decreasing and then increasing with the increase of potential, indicating the OER at higher potentials mainly occurs on the Co surface. Moreover, the obvious variation of $\mathrm{Fe}-\mathrm{Fe}$ and $\mathrm{Co}-\mathrm{Co}$ bond lengths is found in the generation process of $\mathrm{OOH}^{*}$ and $\mathrm{O}^{*}$ species, respectively, which further implies that the active positions of the ORR 
and OER are mainly provided by the Fe and Co species. The investigations prove that the existence of FeCo could give more active sites for OER and ORR. A similar structure of alloy nanoparticles wrapped by nanotubes was proposed using an atomic modulation strategy for $\mathrm{FeCo}$-nitrogen-carbon electrodes by Su et al. [42]. By investigating by both experimental and simulation devices, an efficient synergetic couple between FeCo alloy and $\mathrm{N}$-doped carbon nanotubes is reported as an appreciable coordination structure and electronic environment. Due to the effects provided, the catalyst exhibits a small operating potential of $1.73 \mathrm{~V}$ to reach $10 \mathrm{~mA} \mathrm{~cm}^{-2}$ for OER in $0.1 \mathrm{M} \mathrm{KOH}$. As we know, single metal-based $\mathrm{Fe}-\mathrm{N}-\mathrm{C}$ materials often lack efficient OER catalytic activity. According to this work, the poor OER activities of $\mathrm{Fe}-\mathrm{N}-\mathrm{C}$-based materials are mainly because of the semi-conductive $\mathrm{FeOOH}$ species formed in OER process. The weak FeOOH bonding strength also poisons the Fe sites and consequently falls inactive. As a result, heteroatom doping is a facile strategy to improve the activities, where the highly OER active Co is thought of as a suitable candidate. This work prepares the efficient N-GCNT/FeCo with bamboo-like structures by a one-pot temperature-programmed calcination process. Investigated by XPS, it is found that the bimetal alloy with appropriate Co incorporation content in $\mathrm{N}-\mathrm{GCNT} / \mathrm{FeCo}$ can dominantly promote the generation of pyridinic N. As widely acknowledged electro-active sites, the electron-accepting pyridinic $\mathrm{N}$ species can give a quite large positive charge density to the adjacent $\mathrm{sp}^{2}$-bonded $\mathrm{C}$ atoms, accelerate adsorption of oxygen-containing reactant such as $\mathrm{OH}^{-}$and $\mathrm{O}_{2}$, and facilitate the electron transfer between the surface of the electrocatalyst and intermediates, thus efficiently improving OER activities with fast reaction kinetics. These mechanisms are also proved by DFT calculations shown in Figure 11c-g. For OER, the rate-determining step is the second electron transfer step for the prepared three electrocatalysts, with the values of $U_{\mathrm{L}}(\mathrm{OER})$, $1.16 \mathrm{~V}$ for N-GCNT, $1.45 \mathrm{~V}$ for N-GCNT/Fe, and $0.58 \mathrm{~V}$ for N-GCNT/FeCo. Obviously, N-GCNT/FeCo exhibits the most efficient catalytic activity for OER. Therefore, DFT calculations are highly consistent with the experimental data, shedding light on the synergetic effects between FeCo alloy nanoparticles and N-GCNT in forming considerable surface electronic modulation and thereby promoting the OER performance.

MOFs are also acknowledged as efficient precursors for alloy-based catalysts. Feng et al. [65] prepared a series of $\mathrm{CoM}(\mathrm{M}=\mathrm{Fe}, \mathrm{Cu}, \mathrm{Ni}$ )-embedded nitrogen porous carbon frameworks by a facile thermal conversion method with metal-doped zeolitic imidazolate frameworks (ZIF). The optimized $\mathrm{Co}_{0.75} \mathrm{Fe}_{0.25}$ nitrogen-doped carbon catalyst shows a low overpotential of only $303 \mathrm{mV}$ to reach the current density of $10 \mathrm{~mA} \mathrm{~cm}^{-2}$. For these samples, the incorporation of the second metal into Co-NC not only provides more metal-centered active sites, but also changes the electronic environment of the centers in $\mathrm{Co}-\mathrm{NC}$, improving the catalytic activity. The metal alloy and nitrogen could also trigger the OER activity of the inactive carbon atoms. The enhanced outer graphitic layers would act as active sites for OER. By now, it has been clarified that the metal sites of CoFe alloy could catalyze the OER.

Although the $\mathrm{N}$-doped carbon-based FeCo bimetal alloy materials display excellent activities towards OER, hybrid catalysts combining alloy nanoparticles with other metals or derivatives have also been developed by researchers. By electrospinning $\mathrm{Fe} / \mathrm{Co}-\mathrm{N}$ compounds with polyvinylpyrrolidone (PVP) and polyacrylonitrile (PAN), hybrid mesoporous Fe/Co-N-C nanofibers with embedded FeCo alloy nanoparticles were fabricated by Li et al. [40] The FeCo alloy nanoparticles distribute on the surface of nanofibers uniformly. With increased Fe and Co precursors, the resulting OER activities are improved, indicating FeCo nanoparticles are active towards OER. Zhu et al. [66] used an in-situ coupling approach to prepare $\mathrm{FeCo}$ alloys and $\mathrm{Co}_{4} \mathrm{~N}$ hybrid for catalyzing OER. The active hybrid is obtained through a facile pyrolysis of bimetallic porous phthalocyanine-based network. The simultaneous formation of multiple diverse $\mathrm{FeCo}$ alloys and $\mathrm{Co}_{4} \mathrm{~N}$ nanoparticles plays a crucial role for the excellent OER performance. The new catalyst shows an outstanding OER performance at low overpotential of $280 \mathrm{mV}$ to achieve $10 \mathrm{~mA} \mathrm{~cm}{ }^{-2}$ and high durability in an alkaline solution. $\mathrm{Co}_{3} \mathrm{O}_{4}$-hydroxides (LDHs) were used as precursors to fabricate $\mathrm{Co}_{3} \mathrm{O}_{4}$-doped $\mathrm{Co} / \mathrm{CoFe}$ nanoparticles by thermal decomposition by $\mathrm{Li}$ et al. [67] The prepared core-shell structure performs excellent OER activities. 


\subsubsection{Bimetal Oxides and Hydroxides Electrocatalysts}

The development of OER electrocatalysts has been impeded by identifying the catalytic active sites accurately. However, it is acknowledged that the oxides and (oxy)hydroxides for transition metals, especially $\mathrm{Fe}, \mathrm{Co}$, and $\mathrm{Ni}$, are active for OER.

As for $\mathrm{Fe}-\mathrm{Co}$ bimetal oxides, there have been conflicting reports about whether the incorporation of Fe into $\mathrm{CoO}_{x}$ could benefit the OER activity, due to the difficulty of quantifying the number of active sites. A binary transition-metal oxide complex was synthesized by Peng et al. [5] with morphology of hollow nanoparticles. Utilizing the Kirkendall effect, the hollow polycrystalline and highly disordered nanoparticles are formed with OER activity in alkali media. Hollow Fe-Co oxide NPs with different ratios of $\mathrm{Fe} / \mathrm{Co}$ were prepared and their electrocatalytic performance were tested. The optimal $\mathrm{Fe}_{\mathrm{x}} \mathrm{Co}_{100-\mathrm{x}}$ oxides NPs results in an excellent performance, and a current density of $10 \mathrm{~mA} \mathrm{~cm}^{-2}$ is achieved at an overpotential of $\sim 0.30 \mathrm{~V}$. This work shows that the Co-rich surfaces are active while the presence of surface iron is also critical. However, the origin of the outstanding OER performance is still blurry. To further clarify the intrinsic electrocatalytic activities of Fe-doped cobalt oxides for OER, theoretical studies were performed by Kim et al. [68] using first-principle calculations. The OER mechanisms are analyzed for each site containing the terminal and bridge oxygen sites neighboring the dopant or Co cations in the molecules. The oxide cluster model shown in Figure 12a,b illustrates the dopant terminal site, bridge site, and cobalt terminal site. The mechanisms and the free-energy diagrams for OER of each site of the model were investigated by DFT and given in this work. As a result, the main efficiency of the enhanced OER activity of Fe-containing cobalt oxides are supplied by new active bridge sites, rather than the improvement of the terminal sites. This work helps to deeply demonstrate the OER activity of the Fe-doped Co-oxide-based materials.
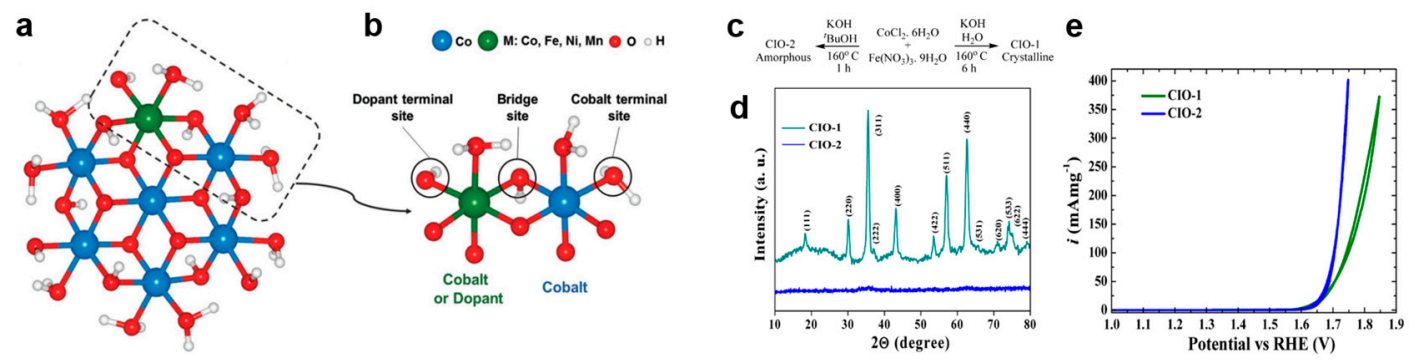

Figure 12. (a) Original or Fe-doped $\mathrm{Co}$ oxide cluster model with the composition $\mathrm{Co}_{6} \mathrm{FeO}_{24} \mathrm{H}_{27}$. (b) The part of the cluster containing the oxygen sites regarded as the OER mechanism simulation. The cobalt terminal site represents the terminal oxygen connected to the Co ion, located at the second coordination range of the dopant. The dopant terminal site represents the terminal oxygen connected to the doped Fe. The bridge site represents the $\mu 2-\mathrm{O}$ bonding the doped Fe and Co ion, reproduced with permission from [68]. Copyright CCC Republication, 2018. (c) Synthetic process for the fabrication of the electrocatalysts CIO- 1 and CIO-2; (d) powder XRD patterns of CIO- 1 and CIO-2. The peaks of CIO-1 correspond to $\mathrm{CoFe}_{2} \mathrm{O}_{4}$ spinel whereas no apparent peaks are observed for CIO-2; (e) cyclic voltammograms (CV) of CIO-1 and CIO-2 in $0.1 \mathrm{M} \mathrm{KOH}$ with a scan rate of $6 \mathrm{mV} \mathrm{s}^{-1}$. Reproduced with permission from [69]. Copyright American Chemical Society, 2014.

Except for the discussions for the original mechanisms, there are also various reports about the materials themselves. For instance, Indra et al. [69] made a comparison between the amorphous and crystalline cobalt iron oxides. By differing solvents and reaction time (Figure 12c) in a simple solvothermal process, a highly crystalline (CIO-1: $\mathrm{CoFe}_{2} \mathrm{O}_{4}$ ) and an amorphous cobalt iron oxide (CIO-2: $\mathrm{CoFe}_{2} \mathrm{O}_{\mathrm{n}}, \mathrm{n}=\sim 3.66$ ) were prepared. As demonstrated in Figure 12e, CIO-2 exhibits higher OER activity than $\mathrm{CIO}-1$ in alkaline condition, indicating better OER performance. Compared with CIO-1, CIO-2 includes a larger content of low spin $\mathrm{Co}^{3+}$ species, evidencing that the $\mathrm{Co}^{3+}$ in the octahedral structure improves OER, while the $\mathrm{Co}^{2+}$ in the tetrahedral sites is inactive. In addition, from the XPS spectra for 
Co $2 p$ edges of the samples before and after electrochemical measurement, it can be observed that the peak broadens and shifts to higher energy for both CIO-1 and CIO-2, proving the generation of $\mathrm{Co}^{3+}$ during the OER. Similarly, the same results are found in Fe XPS 2p peaks. As a result, electrocatalytic active $\mathrm{Co}^{3+}$ and $\mathrm{Fe}^{3+}$ are generated through the OER process, leading to higher OER activities.

Cobalt iron hydroxide is also regarded as a precious OER electrocatalyst as it can easily combine with oxygen-containing groups and then change into OER reaction intermediates. Babar et al. [6] reported a convenient and scalable approach to obtain a 3D self-supported NF electrode substrate integrated with $\mathrm{Co}-\mathrm{Fe}$ hydroxide. The obtained $\mathrm{CoFe} / \mathrm{NF}$ electrode performs excellent OER activity with a small potential of $1.45 \mathrm{~V}$ to reach $10 \mathrm{~mA} \mathrm{~cm}^{-2}$. Synergistic effects between the metallic characters of $\mathrm{Fe}$ and $\mathrm{Co}$ are the main reason for the excellent electrocatalytic activity. The introduction of Fe could significantly promote the OER performance of $\mathrm{Co}(\mathrm{OH})_{2}$ catalyst because easier $\mathrm{OH}^{-}$intercalation can be achieved by increasing disorder/porosity as well as more defect or edge sites on $\mathrm{Co}(\mathrm{OH})_{2}$ surface. The $\mathrm{CoFe} / \mathrm{NF}$ facilitates the proton-coupled electron transfer steps by forming oxo species at lower potentials, due to the synergistic couple of $\mathrm{Co}$ and Fe. Jin et al. [12] also presented an economic and highly efficient catalyst for OER, which was denoted as $\alpha-\mathrm{Co}_{1-m} \mathrm{Fe}_{m}(\mathrm{OH})_{2}$. The obtained layered $\alpha-\mathrm{Co}_{4} \mathrm{Fe}(\mathrm{OH})_{x}$ nanosheets can catalyze OER at a low potential of $1.525 \mathrm{~V}$ to achieve $10 \mathrm{~mA} \mathrm{~cm}^{-2}$ and a low Tafel slope of $52 \mathrm{mV} \mathrm{dec}^{-1}$. During the OER test, the first $\mathrm{CV}$ cycle of $\alpha-\mathrm{Co}_{4} \mathrm{Fe}(\mathrm{OH})_{\mathrm{X}}$ shows a much higher anodic peak than the second CV cycle without reduction peak (Figure 13a,b), which coincides with the previously published result that $\mathrm{Co}(\mathrm{OH})_{2}$ could be irreversibly changed into CoOOH. It is noticeable that with the increased $\mathrm{Fe}$, the anodic wave of $\mathrm{Co}^{2+/ 3+}$ shifts positively. This indicates that an evident electronic function between $\mathrm{Co}$ and Fe could modify the electronic environment of $\alpha-\mathrm{Co}(\mathrm{OH})_{2}$ and make $\mathrm{Co}^{2+}$ oxidation more difficult. Besides, the Fe enlarges the spacing between the $\mathrm{Co}(\mathrm{OH})_{2}$ sheets and increases the electrochemical surface area. The DFT calculations also demonstrate that the introduction of Fe influences the adsorption energy of $\mathrm{O}$ and $\mathrm{OH}$, leading to a higher $\Delta G_{\mathrm{O} *}^{0}-\Delta G_{\mathrm{HO}}^{0}$ * and lower overpotential for OER (Figure 13c-g).

Burke et al. [14] systematically investigated the function of Fe in Co-based materials and the intrinsic OER activity of $\mathrm{Co}_{1-x} \mathrm{Fe}_{x}(\mathrm{OOH})$. The intrinsic OER $p$ of $\mathrm{Co}_{1-x} \mathrm{Fe}_{x}(\mathrm{OOH})$ is demonstrated by turnover frequency (TOF) calculation, which is defined as the number of $\mathrm{O}_{2}$ molecules produced per second per active site. As Figure 13h,i shows, the intrinsic activity of $\mathrm{Co}_{1-\mathrm{x}} \mathrm{Fe}_{\mathrm{x}}(\mathrm{OOH})$ is $\sim 100$-fold higher for $\mathrm{x} \approx 0.6-0.7$ than for $\mathrm{x}=0$ on a per-metal TOF basis. The role of $\mathrm{Fe}$ in $\mathrm{Co}_{1-\mathrm{x}} \mathrm{Fe}_{\mathrm{x}}(\mathrm{OOH})$ for OER could be divided into three aspects. For the structure and electrolyte accessibility, Fe incorporation would allow for easier $\mathrm{OH}^{-}$intercalation and facilitate the transformation from $\mathrm{Co}(\mathrm{OH})_{2}$ into $\mathrm{CoOOH}$ evidently, due to the increased disordered structure. For the effective electrical conductivity, the $\mathrm{FeOOH}$ films exhibit apparently poorer conductivity than those with Co. However, the addition of Fe into $\mathrm{CoOOH}$ does not enhance the conductivity of $\mathrm{Co}_{1-x} \mathrm{Fe}_{\mathrm{x}}(\mathrm{OOH})$ compared with $\mathrm{CoOOH}$; there is only a shift towards more anodic potentials for the beginning of the $\mathrm{Co}^{2+/ 3+}$ oxidation peak after $\mathrm{Fe}$ incorporation. For the active sites, the results indicate that the intrinsic activity of the iron-based sites is $\sim 130$-fold higher than that of the cobalt-based sites. The element Fe provides the primary OER activity while $\mathrm{CoOOH}$ provides an inherently large surface-area and superior conductivity. 

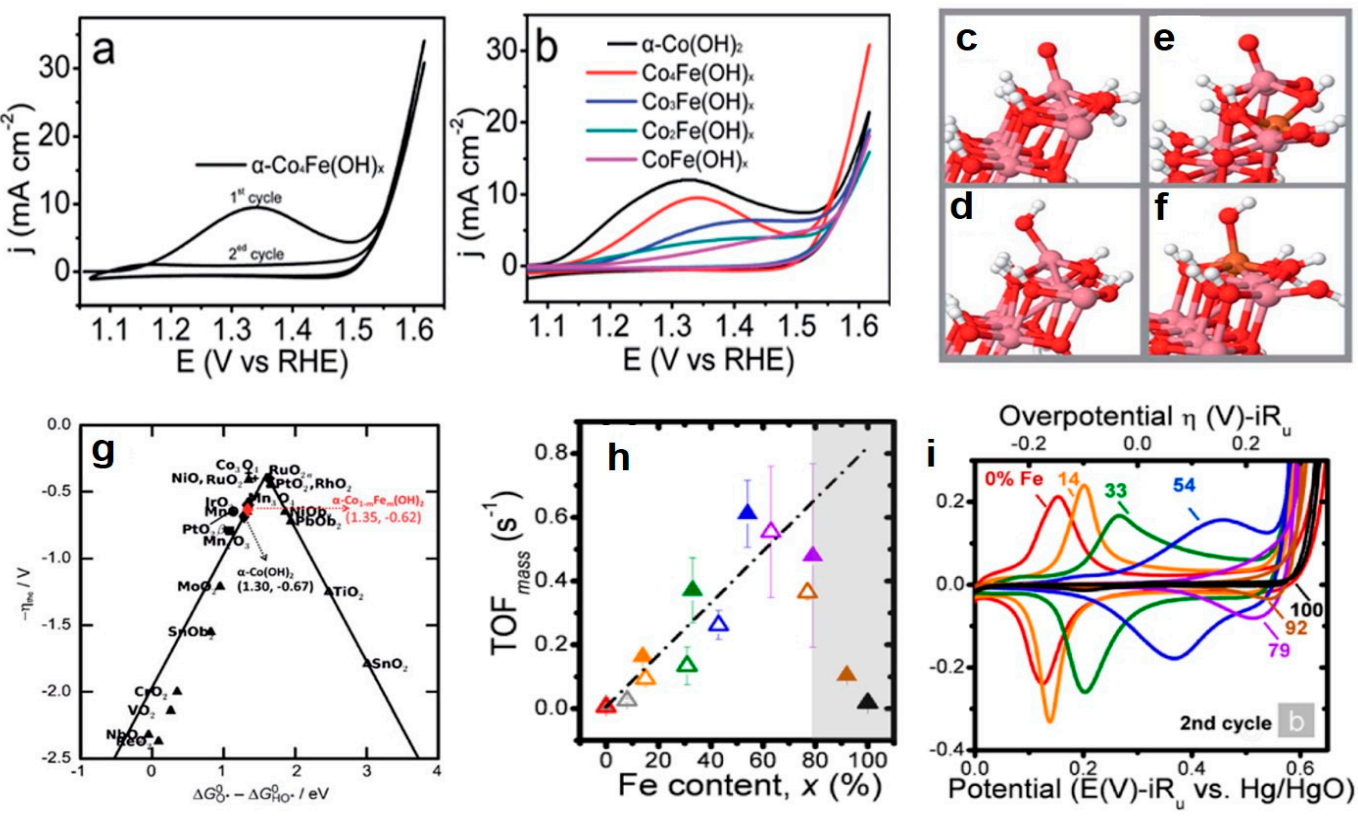

Figure 13. (a) Voltammetry of $\alpha-\mathrm{CO}_{4} \mathrm{Fe}(\mathrm{OH})_{\mathrm{x}}$ in purified $\mathrm{KOH}$ showing the difference between the first and second $\mathrm{CV}$ cycles; (b) the first voltammetry of different $\mathrm{Co} / \mathrm{Fe}$ ratio catalysts showing a systematic anodic shift of the (nominally) $\mathrm{Co}^{2+/ 3+}$ wave with the increasing Fe content, $\mathrm{O}$ binding on $(\mathbf{c}) \mathrm{Co}(\mathrm{OH})_{2}$ and (d) $\alpha-\mathrm{Co}_{1-\mathrm{m}} \mathrm{Fe}_{\mathrm{m}}(\mathrm{OH})_{2}, \mathrm{OH}$ binding on $(\mathbf{e}) \mathrm{Co}(\mathrm{OH})_{2}$ and $(\mathbf{f}) \alpha-\mathrm{Co}_{1-\mathrm{m}} \mathrm{Fe}_{\mathrm{m}}(\mathrm{OH})_{2}$ (red: Oxygen; pink: Cobalt; brown: Ferrum; white: Hydrogen); (g) the positions of the pristine and Fe-doped $\alpha-\mathrm{Co}(\mathrm{OH})_{2}$ on the volcano curve, reproduced with permission from [12]. Copyright Royal Society of Chemistry, 2017. (h) Turnover frequency (TOF) data depicted based on the total film mass and composition assuming all metal sites are available for catalysis; (i) voltammetry of $\mathrm{Co}_{1-\mathrm{x}} \mathrm{Fe}_{\mathrm{x}}(\mathrm{OOH})$ showing systematic anodic shift of the (nominally) $\mathrm{Co}^{2+/ 3+}$ wave with increasing Fe content, reproduced with permission from [14]. Copyright American Chemical Society, 2015.

Although bimetal oxide and hydroxide have been regarded as outstanding catalysts for OER, researchers still make efforts to combine them with other components to improve the electrocatalytic activity. Chen et al. [70] synthesized electrochemically tuned cobalt-nickel-iron oxides by an in situ electrochemical oxidation approach from their corresponding sulfides. An electrochemical deposition-sulfurization-tuning strategy was applied for nano-porous transition metal oxides with significantly enhanced OER activity. The prepared $\mathrm{Co}-\mathrm{Ni}-\mathrm{Fe}$ oxides in situ fabricated on the 3D carbon-fiber electrode exhibits a low potential of $1.462 \mathrm{~V}$ at $10 \mathrm{~mA} \mathrm{~cm}{ }^{-2}$ and a small Tafel slope of $37.6 \mathrm{mV} \mathrm{dec}{ }^{-1}$. By this approach, the OER activity is enormously enhanced owing to an enlargement of specific surface area and active catalytic sites caused by the in situ electrochemical tuning. Zhang et al. [71] developed cobalt-iron phytate (Co-Fe-phy) nanoparticles as OER catalyst, which has a big degree of amorphization, nano-porous geometry, and large electrochemically active surface area. The hybrid exhibits a low overpotential of $278 \mathrm{mV}$ at $10 \mathrm{~mA} \mathrm{~cm}^{-2}$ and a small Tafel slope of $34 \mathrm{mV} \mathrm{dec}^{-1}$ in $1.0 \mathrm{M} \mathrm{KOH}$. As previously reported, the bulky phosphate could induce the crystal lattice of the metal to become disordered. Hence, enormous phytate groups may play a similar function in generation of the $\mathrm{Co}-\mathrm{Fe}-$ phy, resulting in larger surface area and sufficient active sites. According to the role of $\mathrm{Fe}$, it is observed that the oxidation peak of $\mathrm{Co}-\mathrm{Fe}-$ phy shifts positively and becomes larger compared to Co-phy. The phenomenon could be explained as the doping iron tuning the electronic states of cobalt-based materials. Similar discussion was given by Liu et al. [72] who reported a facile approach to a porous iron-cobalt phosphide (Fe-Co-P) alloy structure with good conductivity employing an Fe-Co bimetal MOF as a precursor. The obtained complex possesses outstanding OER performance with the typical $10 \mathrm{~mA} \mathrm{~cm}^{-2}$ being reached at $1.482 \mathrm{~V}$. Density of states (DOS) values of the $\mathrm{Fe}-\mathrm{Co}-\mathrm{P}$ and the compared $\mathrm{FeP}$ and $\mathrm{CoP}$ are calculated to inspect the electronic structures. 
The DOS value of Fe-Co-P has a bigger ratio of states located near the Feimi level than that of FeP and $\mathrm{CoP}$, indicating higher electronic conductivity. The local surface changes of the material during OER are analyzed by XPS. After electrochemical test, an additional evident peak is observed in the Fe $2 \mathrm{p}_{3 / 2}$ spectrum corresponded to the generated FeOOH during the electrochemical process. The Co $2 \mathrm{p}_{3 / 2}$ peaks after OER show a similar valence status with those of fresh $\mathrm{Fe}-\mathrm{Co}-\mathrm{P}$ sample, suggesting the Co element is stable during the reaction. As a result, the Fe is regarded as being beneficial for stabilizing the Co-centered species in a low state, resulting in the simultaneous improvement of activity and durability for OER. Former experimental data and DFT results have demonstrated that the generation of high-oxidation state $\mathrm{M}-\mathrm{OOH}$ intermediates is the rate-determining step for OER. Introducing heteroatoms is thought of as an efficient way to induce easier transformation toward $\mathrm{M}-\mathrm{OOH}$. The boron could debilitate the $\mathrm{M}-\mathrm{M}$ bonds, thus decreasing the thermodynamic and kinetic barriers for $\mathrm{M}-\mathrm{OOH}$ generation. Chen et al. [18] reported an amorphous $\mathrm{Co}_{\mathrm{x}}-\mathrm{Fe}-\mathrm{B}$ compound with a low overpotential of $0.298 \mathrm{~V}$ at $10 \mathrm{~mA} \mathrm{~cm}^{-2}$ for OER. From the experimental results, the function mechanism of the synergistic effect is demonstrated in Figure 14a; the incorporation of Fe enhances the third step in the OER process, increasing the quantity of $\mathrm{OOH}$ species, while enhancing the conductivity. The existence of $\mathrm{B}$ content decreases the energy barrier for the generation of the $\mathrm{OOH}$.
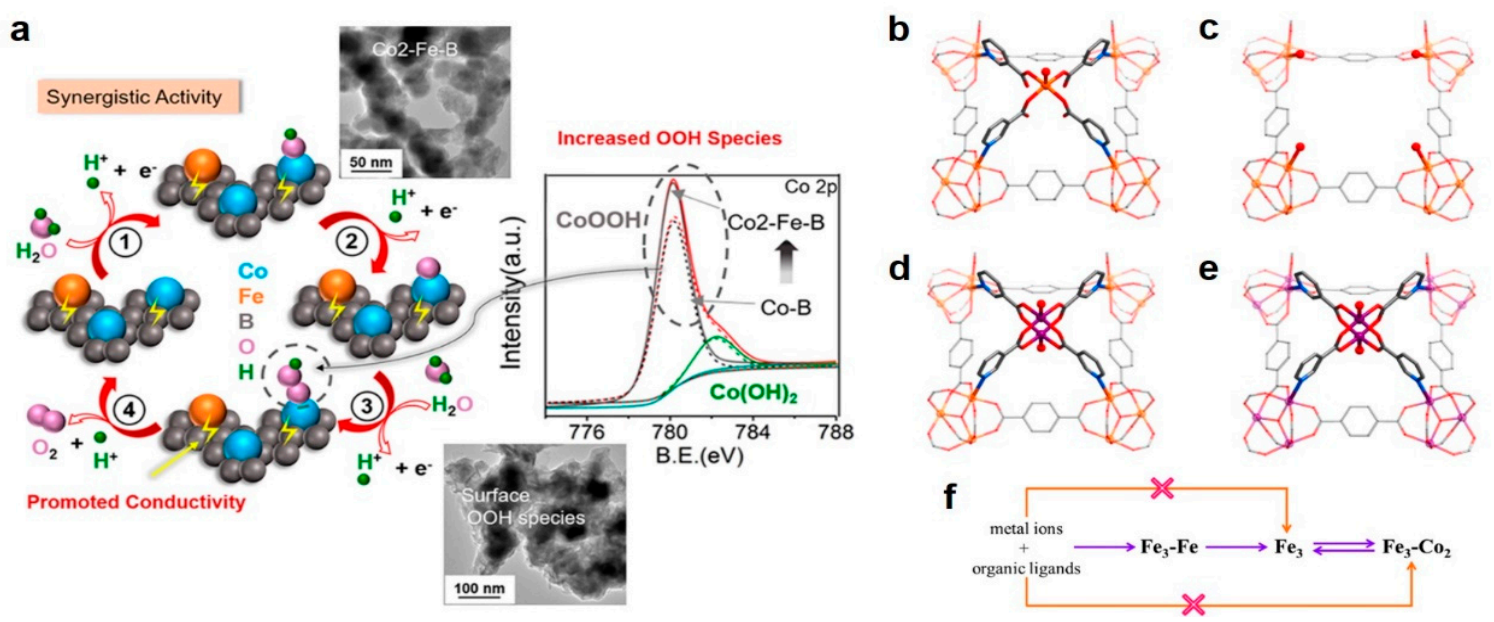

Figure 14. (a) Illustration of the OER mechanism of the synergistic couple of $\mathrm{Co}_{2}-\mathrm{Fe}-\mathrm{B}$, reproduced with permission from [18]. Copyright American Chemical Society, 2017. Key partial structures of (b) $\mathrm{Fe}_{3}-\mathrm{Fe}$, (c) $\mathrm{Fe}_{3}$, (d) $\mathrm{Fe}_{3}-\mathrm{Co}_{2}$, and (e) $\mathrm{Co}_{3}-\mathrm{Co}_{2} ;$ (f) synthesis demonstration of $\mathrm{Fe}_{3}-\mathrm{Co}_{2}$, reproduced with permission from [73]. Copyright American Chemical Society, 2018.

\subsubsection{Dual-Metal M-N-C Site-Based Electrocatalysts}

As a facile method to design dual-metal sites, the construction of metal-organic frameworks has emerged as a series of potential electrocatalysts, as the unsaturated metal centers tend to be active catalytic sites. An unusual host/guest geometry and modular synthetic strategy was provided by Shen et al. [73] through a two-step, single-crystal to single-crystal, post-synthetic modifications, a thermal-, water-, and alkaline-stable MOF $\left[\left\{\mathrm{Fe}_{3}\left(\mu_{3}-\mathrm{O}\right)(\mathrm{bdc})_{3}\right\}_{4}-\left\{\mathrm{Co}_{2}(\mathrm{na})_{4}\left(\mathrm{~L}^{\mathrm{T}}\right)_{2}\right\}_{3}\right]$ $\left(\mathrm{H}_{2} \mathrm{bdc}=1\right.$,4-benzenedicaboxylic acid, Hna = nicotinic acid, $\mathrm{L}^{\mathrm{T}}=$ terminal ligand $)$-containing dicobalt cluster. The hybrid MOF processes high electrocatalytic oxygen evolution activity with a low overpotential of $225 \mathrm{mV}$ at $10 \mathrm{~mA} \mathrm{~cm}^{-2}$ in aqueous solution at $\mathrm{pH}=13$. By constructing the dual-metal structure, the paddle-wheel type dinuclear metal carboxylate cluster $\mathrm{M}_{2}(\mathrm{RCOO})_{4}\left(\mathrm{~L}^{\mathrm{T}}\right)_{2}$ could be stabilized in water since the specific coordination geometries give them high adsorption affinities and low chemical stabilities. The chemical durability of the $\mathrm{Fe}_{3}-\mathrm{Co}_{2}, \mathrm{Fe}_{3}, \mathrm{Fe}_{3}-\mathrm{Fe}$, and $\mathrm{Co}_{3}-\mathrm{Co}_{2}$ (Figure 14b-f) are obtained in aqueous solution at different $\mathrm{pH}$ values. The $\mathrm{Fe}_{3}-\mathrm{Co}_{2}, \mathrm{Fe}_{3}$, and $\mathrm{Fe}_{3}-\mathrm{Fe}$ can remain undamaged at $\mathrm{pH}=13$, whereas $\mathrm{Co}_{3}-\mathrm{Co}_{2}$ collapses even at $\mathrm{pH}=7$. In the OER electrocatalytic investigations, the $\mathrm{Fe}_{3}-\mathrm{Co}_{2}$ sample gives much higher activity than the single metal samples, including 
lower overpotential and smaller Tafel slope, indicating the synergistic couple between Fe and Co. The intrinsic synergistic effect has been proved by dual-metal single-atom catalysts. Due to the structural homogeneity, single-atom catalysts can facilitate precise identification and characterization of catalytic active sites. The high atom economy of the single-atom catalysts also coincides with the request of sustainable development [74]. Using two types of templates concurrently, Li et al. [75] reported a hierarchical meso/microporous $\mathrm{FeCo}-\mathrm{N}_{\mathrm{x}}-\mathrm{C}$ nanosheets with high OER activity. The synergistic application of two kinds of templates, an active metal salt and silica nanoparticles, achieves a reversible catalyst of efficient OER-ORR performance. Compared with single-metal $\mathrm{Fe}-\mathrm{N}_{\mathrm{x}}-\mathrm{CN}$ electrocatalyst, the obtained bimetal $\mathrm{FeCo}-\mathrm{N}_{\mathrm{x}}-\mathrm{NC}$ possesses lower onset potential and smaller Tafel slope, suggesting the coupling of $\mathrm{Fe}$ and $\mathrm{Co}$ with doped nitrogen can tune the electronic environment and surface polarities and improve the OER performance.

\subsection{ORR}

As the reverse reaction of OER, ORR occurs in the cathode for recharging process of the metal-air batteries and fuel cells. Platinum-based materials are thought of as the most efficient catalysts for proton exchange membrane fuel cells (PEMFCs) and direct methanol fuel cells (DMFCs). However, due to the high cost and scarcity of $\mathrm{Pt}$, it is essential to develop low-cost materials with high ORR efficiency. The charge transfer between different metal sites modulates the electronic structures, enhancing the ORR activity by adjusting the adsorption energy for the intermediates. Among the non-noble metal catalysts, $3 \mathrm{~d}$ transition metal-based materials are most promising for their unique catalytic properties.

\subsubsection{Bimetallic Alloy-Based Electrocatalysts}

For ORR, Fe-Co alloy-based doped carbon hybrid materials are highly desirable due to the various active sites. Sultan et al. [76] reported a precisely tuned atomic ratio of Fe and Co embedded in nitrogen-doped graphitic tube (NCT). The optimal $\mathrm{Co}_{1.08} \mathrm{Fe}_{3.34}$ complex with $\mathrm{M}-\mathrm{N}$ bonds exhibits remarkable ORR activities of an onset potential of $1.03 \mathrm{~V}$ and half-wave potential of $0.94 \mathrm{~V}$, surpassing $\mathrm{Pt} / \mathrm{C}$ in $0.1 \mathrm{M} \mathrm{KOH}$. The excellent ORR performance is ascribed to the coexistence of $\mathrm{Co}-\mathrm{N}, \mathrm{Fe}-\mathrm{N}$, and sufficient metallic FeCo alloys, which are inherently better at interacting with reactants and favor faster electron movement due to the presence of lone-pair electrons. The Fourier transform extended X-ray absorption fine structure (FT-EXAFS) analysis of cobalt and iron reveals the coexistence of peak corresponding to $\mathrm{Co}(\mathrm{Fe})-\mathrm{N}$ and $\mathrm{Co}(\mathrm{Fe})-\mathrm{Co}(\mathrm{Fe})$. Alloying $\mathrm{Fe}$ and $\mathrm{Co}$ induces favorable changes in intrinsic properties by altering the DOS at the Fermi level of the metallic sites, which enhance their catalytic activity to a large extent. Therefore, not only the acknowledged $\mathrm{M}-\mathrm{N}_{\mathrm{x}}$, but also FeCo alloy provides numerous active sites for ORR, resulting in high electrocatalytic activity for ORR. Moreover, the high activity and stability also originate from nitriding and encapsulation in the graphitic shell, which improves the exposed surface of active sites, electronic, and mass transfer. For ORR, a specific class of metal/N-doped carbon matrix materials, which include $\mathrm{N}$-coordinated sites with iron or cobalt embedded, have been regarded as promising electrocatalysts. Similar to the mechanisms of nitrogen doping, some nitrogenous functional groups like 2-pyrridone could also facilitate the complexation of metal irons, generating applicable precursors of ORR electrocatalysts. For example, Lim et al. [77] gave a highly efficient non-noble metal catalyst based on poly(vinylpyrrolidone)-wrapped carbon nanotubes combined with Fe-Co metal ions. First, the nanotubes and PVP are mixed in water with ultrasonic treatment to obtain a durable dispersion of MWCNT-PVP. A metal loading is then added to the dispersion and stirred. After pyrolysis in $\mathrm{NH}_{3}$, the hybrid material with $\mathrm{Fe}$ and $\mathrm{FeCo}$ alloy nanoparticles wrapped in $\mathrm{N}$-doped carbon nanotubes is prepared. The total metal loading of the non-noble metal in the FeCo-CNT electrocatalysts is about $1 \mathrm{wt} \%$. During the process, the metal ions are chemisorbed onto the 2-pyttidone groups, because of the high polarity of the near-planar lactam ring. It is notable that according to XPS and XRD results, the nature of metallic nanoparticles has an effect on the formation of nitrogen. Fe nanoparticles induce the generation of graphitic-carbon, while Co nanoparticles promote the formation of pyridinic-nitrogen and protonated pyridyl moiety. 
Therefore, the alloy particles have an effect on the ORR performance by both taking part in the reaction and determining the type of the N species. The MWCNT-FeCo catalyst exhibits an enormous improvement in the ORR performance with an onset potential and half-wave potential of $0.82 \mathrm{~V}$ and $0.73 \mathrm{~V}$ compared with the MWCNT-Fe and MWCNT-Co. The improved activities originate from the active sites provided by FeCo alloy and metal- $\mathrm{N}_{4}$ cores. The $\mathrm{Co}-\mathrm{N}_{4}$ and $\mathrm{Fe}-\mathrm{N}_{4}$ cores are thought to generate a face-to-face bimetal structure with a specified stereo distance, which could induce easy reduction of oxygen to water and facilitate ORR process.

As a typical type of porous materials, MOF materials have been considered as suitable precursors to derive catalysts with the $\mathrm{M}-\mathrm{N}_{\mathrm{x}}$ active sites for ORR. Guan et al. [78] developed the "MOF-in-MOF hybrid" confined pyrolysis method to prepare porous Fe-Co alloy/N-doped carbon cages. The obtained the obtained $\mathrm{Fe}_{0.3} \mathrm{Co}_{0.7} / \mathrm{BC}$ with porous structures shows superior ORR activity with a half-wave potential of $0.88 \mathrm{~V}$, which is higher than the commercial $\mathrm{Pt} / \mathrm{C}$ electrocatalysts $(0.855 \mathrm{~V})$. The specific strategy from MOF provides sufficient $\mathrm{N}$-coordinated bimetallic active sites together with graphitic $\mathrm{N}$-doped carbon matrix, rendering high activity and selectivity, while the porous structure also improves the mass and charge transport.

The roles of the alloy nanoparticles and $\mathrm{M}-\mathrm{N}_{\mathrm{x}}$ sites for ORR were further provided by Tan et al. [79]. A nanofiber network of bimetal/nitrogen co-doped carbon electrocatalyst for ORR shows excellent activity with the peak potential ( $\mathrm{E}_{\text {peak }}$ ) at $0.85 \mathrm{~V}$. From the TEM and XRD patterns, both cubic $\mathrm{CoFe}_{2} \mathrm{O}_{4}$ and cubic FeCo alloy are encapsulated in the N-doped carbon shells. XPS spectrum also shows Fe and $\mathrm{Co}$ are co-doped into carbon. The introduction of metals into a N-doped carbon system can form different intrinsic active sites such as $\mathrm{M}-\mathrm{N}_{\mathrm{x}}$, which gives an indispensable effect on the substantial improvement of the ORR activity. After the acid-leached dispose for the catalyst, a significant inferior ORR activity is observed with a potential shift by $51 \mathrm{mV}$. It can be concluded that upgradation originates from the activity provided by a bimetallic center $\left(\mathrm{CoFe}_{2} \mathrm{O}_{4} / \mathrm{FeCo}\right)$. Regarding the role of the metallic $\mathrm{Co}$ and $\mathrm{Fe}$, the Nyquist plots also indicate that the Fc-F (ferrocenoyl-phenylalanine)/Co@N-C800 shows the lowest charge-transfer resistance, which is possibly due to the Fe and Co inducing the graphitization of carbon during the pyrolysis process. Higher graphitization degree can improve the conductivity and stability of the electrocatalyst, resulting in higher activity. In summary, the excellent performance of the catalyst can be attributed to the coexistence of $\mathrm{FeCo}$ alloy, $\mathrm{CoFe}{ }_{2} \mathrm{O}_{4}$, and $\mathrm{Fe}(\mathrm{Co})-\mathrm{N}_{\mathrm{x}}$ sites, which together provide various active catalytic sites for ORR. The activity from the Fe-Co alloy has been discussed in this paragraph, while the roles of $\mathrm{Co}-\mathrm{Fe}$ bimetal derivatives and metal- $\mathrm{N}_{\mathrm{x}}$ sites will be mentioned in the following parts.

\subsubsection{Bimetal Derivatives Electrocatalysts}

By different precursors and strategies, researchers have developed various bimetal derivatives. The bimetal oxides exhibit excellent activities for ORR. Typically, a template- and surfactant-free strategy was provided by Wang et al. [80] to synthesize a hollow $\mathrm{Co}_{2} \mathrm{FeO}_{4} / \mathrm{MWCNT}$ hybrid. The hollow structure is transformed from the alloy $\mathrm{Co}_{2} \mathrm{Fe}$ nanoparticles via the Kirkendall effect, which is based on the different diffusion speeds of different atoms under certain conditions. The specific hollow morphology with a rough surface can enlarge the active area and improve the mass transfer of the electrolyte, thus enhancing the electrocatalytic activity. In $\mathrm{O}_{2}$-saturated $0.1 \mathrm{M} \mathrm{KOH}$ solution, the oxygen reduction begins at $0.91 \mathrm{~V}$ and the half-wave potential is $0.73 \mathrm{~V}$. The ORR performance of $\mathrm{Co}_{2} \mathrm{FeO}_{4} / \mathrm{MWCNT}$ is obviously higher than that of $\mathrm{Co}_{3} \mathrm{O}_{4} / \mathrm{MWCNT}$ and $\mathrm{Fe}_{2} \mathrm{O}_{3} / \mathrm{MWCNT}$ samples, suggesting the synergistic effect from the $\mathrm{Co}$ and $\mathrm{Fe}$. A similar trend due to the synergistic effect can also be observed in hybrids of metallic nanoparticles with metal oxides. Kim et al. [81] rationally designed a cost-effective and efficient ORR catalyst. Well-distributed nanopolyhedron $\mathrm{Co}_{3} \mathrm{O}_{4}$ grows on nitrogenated graphitic porous two-dimensional layers $\left(\mathrm{C}_{2} \mathrm{~N}\right)$, which encapsulates Fe nanoparticles. The obtained $\mathrm{NP} \mathrm{C}_{3} \mathrm{O}_{4} / \mathrm{Fe} @ \mathrm{C}_{2} \mathrm{~N}$ presents outstanding ORR activity with the onset and half-wave potentials comparable to those of $\mathrm{Pt} / \mathrm{C}$. The excellent ORR performance comes from various reasons, as follows. Firstly, the Fe@ $\mathrm{C}_{2} \mathrm{~N}$ catalyst performs superior oxygen transfer and electron tunneling 
with the polar $\mathrm{C}_{2} \mathrm{~N}$ matrices. The iron cores wrapped by the nitrogenated carbon periphery provide ORR activity and outstanding stability. Then, the increased chemically effective surface area by introducing $\mathrm{Co}_{3} \mathrm{O}_{4}$ is owing to both the improved conductive properties and the induced junction sites due to the strong function between $\mathrm{Co}_{3} \mathrm{O}_{4}$ and carbon matrix. Thirdly, the relative area ratio of $\mathrm{Co}^{3+}$ to $\mathrm{Co}^{2+}$ in the prepared $\mathrm{NPCO}_{3} \mathrm{O}_{4} / \mathrm{Fe} @ \mathrm{C}_{2} \mathrm{~N}$ is higher than that of the hybrid $\mathrm{Co}_{3} \mathrm{O}_{4}+\mathrm{Fe} @ \mathrm{C}_{2} \mathrm{~N}$. This change gives larger number of donor-acceptor reduction sites, which can also improve ORR activity. Finally, the introduction of $\mathrm{Co}^{3+}$ induces an increase in oxygen vacancies and results in a lower ratio of $\mathrm{O}_{\text {lattice }} / \mathrm{O}_{\mathrm{ad}}$, which coincides with the XPS analysis. The lower ratio of $\mathrm{O}_{\text {lattice }} / \mathrm{O}_{\text {ad }}$ indicates the strong interaction between the $\mathrm{NP} \mathrm{Co}_{3} \mathrm{O}_{4} / \mathrm{Fe} @ \mathrm{C}_{2} \mathrm{~N}$ and surface oxygen-adsorbed species, thus enhancing the electrocatalytic activity. Furthermore, the decreased $\mathrm{O}_{\text {lattice }}$ binding energy is proposed to increase the electron donor capacity related to the improved ORR activity, resulting from the synergistic effect between $\mathrm{Co}_{3} \mathrm{O}_{4}$ and $\mathrm{C}_{2} \mathrm{~N}$ network. Wang et al. [82] presented cobalt-iron (II, III) oxide $\left(\mathrm{Co}-\mathrm{Fe}_{3} \mathrm{O}_{4}\right)$ hybrid nanoparticles supported by carbon as an efficient catalyst of ORR in alkaline media. The $\mathrm{Co}-\mathrm{Fe}_{3} \mathrm{O}_{4}$ hybrid nanoparticles embedded on carbon substrate $\left(\mathrm{Co}-\mathrm{Fe}_{3} \mathrm{O}_{4} / \mathrm{C}\right)$ are synthesized by a two-step strategy. Co nanoparticles are prepared first and $\mathrm{Fe}_{3} \mathrm{O}_{4}$ nanoparticles are then fabricated onto them. The $\mathrm{Fe}_{3} \mathrm{O}_{4}$ possesses a cubic inverse spinel structure as well as a close-packed, face-centered cubic configuration of $\mathrm{O}^{2-}$ ions, where each $\mathrm{Fe}^{2+}$ ion occupies half of the octahedral structures while the $\mathrm{Fe}^{3+}$ ions are distributed uniformly between the left octahedral structures and the tetrahedral structures. Based on the square wave voltammetry (SMV) results (Figure 15), it can be concluded that the $\mathrm{Fe}^{2+} / \mathrm{Fe}^{3+}$ transition of $\mathrm{Co}-\mathrm{Fe}_{3} \mathrm{O}_{4} / \mathrm{C}$ apparently has higher potential than $\mathrm{Fe}_{3} \mathrm{O}_{4} / \mathrm{C}$. The anodic shift of $\mathrm{Co}-\mathrm{Fe}_{3} \mathrm{O}_{4} / \mathrm{C}$ will lead to higher ORR activity. From the EXAFS spectrum of Co K-edge and $\mathrm{Fe}$ K-edge, the specific peak is at $3.21 \AA$, which corresponds to the substitution of $\mathrm{Co}^{2+}$ ion by $\mathrm{Fe}^{2+}$ ion to form $\mathrm{Co}-\mathrm{O}-\mathrm{Fe}$ in the hybrid. This replacement may cause the change of the cationic distribution of the catalytic surface, improving the ORR performance. XAS results indicate that the distance of $\mathrm{Fe}-\mathrm{O}$ and the $\mathrm{Fe}-\mathrm{Fe}$ in $\mathrm{Fe}_{3} \mathrm{O}_{4}$ differ throughout the structure, forming lattice strain in $\mathrm{Co}-\mathrm{Fe}_{3} \mathrm{O}_{4} / \mathrm{C}$. The desorption and adsorption of the oxygen-containing $\mathrm{O}$ and $\mathrm{OH}$ intermediates are the two determining steps of ORR, in which the lattice strain would have an effect on the oxygen binding energy and change the ORR efficiency.

(a)

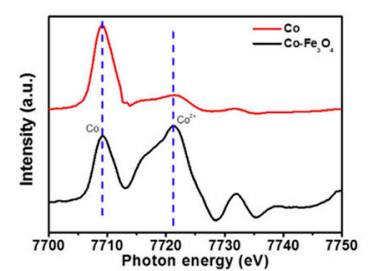

(b)

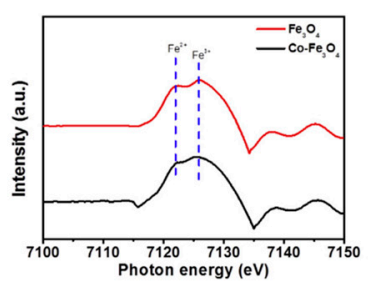

(c)

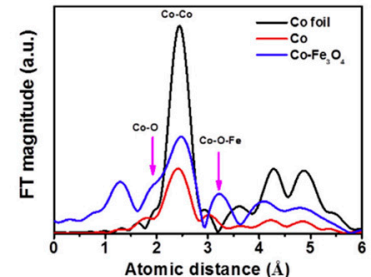

(d)

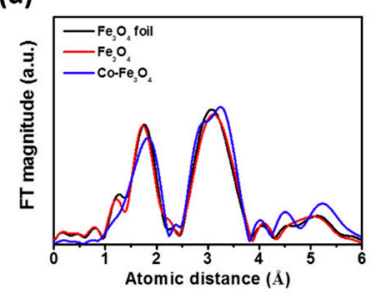

(e)

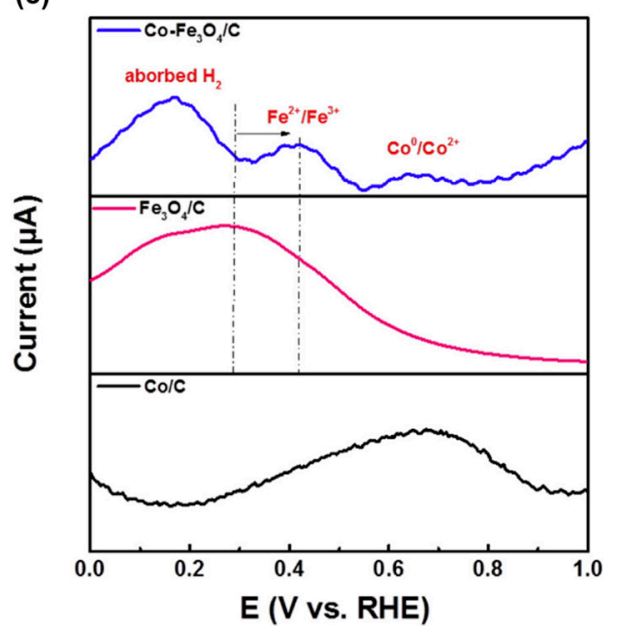

Figure 15. XANES spectra for (a) Co K-edge and (b) Fe K-edge; extended X-ray absorption fine structure (EXAFS) spectra for (c) Co K-edge and (d) Fe K-edge, (e) square wave voltammetry (SWV) curves of $\mathrm{Co}-\mathrm{Fe}_{3} \mathrm{O}_{4} / \mathrm{C}, \mathrm{Fe}_{3} \mathrm{O}_{4} / \mathrm{C}$, and $\mathrm{Co} / \mathrm{C}$ tested in $0.1 \mathrm{M} \mathrm{KOH}$, reproduced with permission from [82]. Copyright Elsevier, 2015.

Apart from metal oxides, there are other classes of derivatives synthesized by scientists. For instance, Jin et al. [83] reported a carbon iron 3D porous carbon-supported carbonate hydroxide 
hydrate as efficient and stable ORR electrocatalysts. This experiment innovatively applies super absorbent polymer (SAP) to provide carbon source, which is the important constituent of baby diapers with efficient adsorption of water and ions. The obtained cobalt iron carbonate hydroxide hydrate in situ loaded on 3D porous carbon (CICHH@C) is prepared by a two-step strategy (Figure 16a-d). Firstly, the mixture is freeze-dried. Then, the resulting mixture is calcined and cooled down to environment temperature. During the preparation, the addition of potassium hydroxide is the key step because it could both accelerate the hydrolysis reactions to form colloid intermediate and induce the graphitization by consuming the amorphous carbon. This CICHH@C exhibits fast ORR kinetics and excellent catalytic activity with a small half-wave potential $(0.780 \mathrm{~V})$ and a low Tafel slope $\left(73 \mathrm{mV} \mathrm{dec}^{-1}\right)$. As a Co-Fe binary material, CICHH is a novel low-cost material for ORR catalysis, of intrinsic superior activity. In addition to SAP, biomass has also been used as precursors for bimetal ORR electrocatalysts. As reported by Sun et al. [84], a three-dimensional hierarchically porous carbon framework embedded with cobalt-iron-phosphide nanodots nanocomposite was synthesized through a lyophilization-pyrolysis-phosphorization process, in which egg white is chosen as the precursor of the $\mathrm{N}$-doped carbon matrix due to its high nitrogen content. The egg white dispersion containing metal ions is freeze-dried and then pyrolyzed in Ar atmosphere to form a 3D honeycomb-like morphology. After a phosphorization process, $\mathrm{CoFeP}$ nanoparticles anchored on the conductive substitute are obtained. The XRD patterns clearly shows that once Co and Fe are doped simultaneously, a synergetic effect would happen between $\mathrm{Fe}$ and $\mathrm{Co}$, leading to the different structures of the phosphides. XPS results also prove the existence of interactions between $\mathrm{Fe}$ and $\mathrm{Co}$, achieving superior catalyst performance. The ORR performance of the materials in $0.1 \mathrm{M} \mathrm{KOH}$ is measured by the rotating disk electrode method. The onset potential and half-wave potential of the CoFeP/EWC sample is $0.94 \mathrm{~V}$ and $0.83 \mathrm{~V}$ respectively, much higher than those of $\mathrm{Co}_{2} \mathrm{P} / \mathrm{EWC}$ and $\mathrm{Fe}_{2} \mathrm{P} / \mathrm{EWC}$.
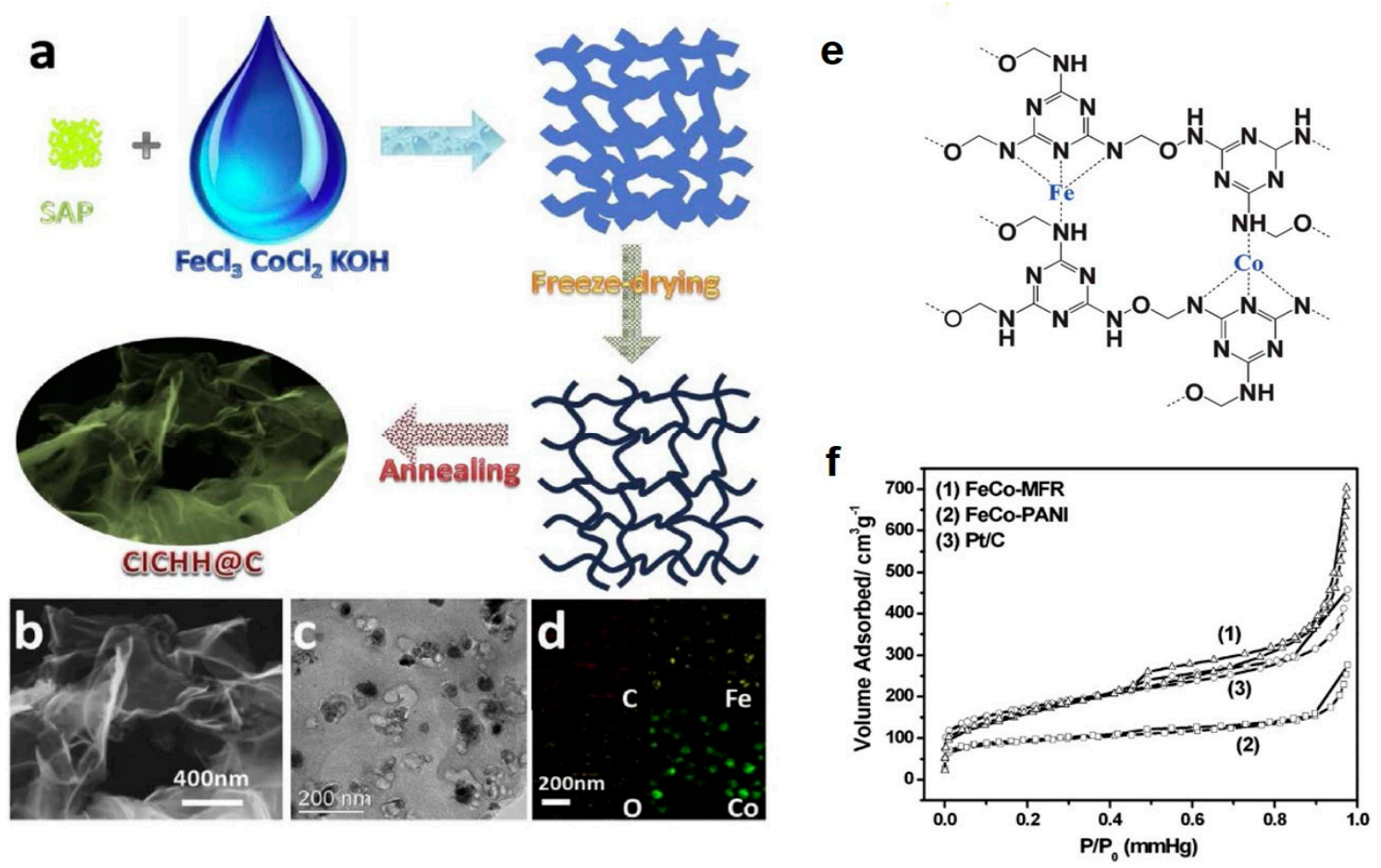

Figure 16. (a) The synthetic scheme of CICHH@C, (b) SEM image of CICHH@C, (c) TEM image of CICHH@C. (d) the C, O, Fe, and Co element mapping of CICHH@C, reproduced with permission from [83]. Copyright Elsevier, 2018. (e) A hypothetical chemical structure of Fe- and Co-coordinating melamine-formaldehyde resin (FeCo-MFR), (f) steady-state polarization curves of ORR for the FeCo-MFR (1), FeCoPANI (2), and Pt/C (3) electrodes in the phosphate buffer solution (PBS) solution, reproduced with permission from [85]. Copyright Royal Society of Chemistry, 2013. 


\subsubsection{Dual Metal M-N-C Sites-Based Electrocatalysts}

To investigate the active $\mathrm{M}-\mathrm{N}_{\mathrm{x}}$ sites of ORR, a series of macrocyclic organic compounds containing both $\mathrm{Co}$ and $\mathrm{Fe}$ are fabricated as precursors of the electrocatalysts. Zhao et al. [85] synthesized a stable $\mathrm{Fe} / \mathrm{Co} / \mathrm{C} / \mathrm{N}$ nano-porous structure using melamine network polymers as carbon and nitrogen source. The predicted chemical structure of the Fe- and Co-coordinating melamine formaldehyde is shown in Figure 16e. The procedure of the synthesis includes hydroxylation of melamine with formaldehyde, polymerization with carbon supports, coordination of transition metals, and pyrolysis. By this method, the $\mathrm{Fe} / \mathrm{Co} / \mathrm{C} / \mathrm{N}$ catalyst behaves with an onset potential of $0.88 \mathrm{~V}$ and a half-wave potential of $0.78 \mathrm{~V}$ in neutral media (Figure 16f). Corresponding to the XPS analysis, pyridinic-N is suggested to constitute the main transition metal-binding site in the $\mathrm{M}-\mathrm{CN}$ material. Protons can be trapped by free pyridinic-N and subsequently transferred to active sites for ORR. To arrange the Co and Fe species with more precise control, Lin et al. [86] altered monomeric iron and cobalt metalloporphyrins to fabricate heterometal-embedded organic conjugate frameworks $(\mathrm{N}-\mathrm{FeCo}-\mathrm{C})$. The ordered distribution of iron and cobalt represents that the innovative method realizes the uniform of active components. The pore volume can also be tuned by utilizing diverse types of monomers with different geometries. In both acid and alkaline electrolyte, the heterometallic product shows excellent ORR activity compared to the pure- $\mathrm{Co}(\mathrm{Fe})$ containing samples. In $0.1 \mathrm{M} \mathrm{KOH}$, the $\mathrm{PCN}-\mathrm{FeCo} / \mathrm{C}$ gives the onset potential of $0.90 \mathrm{~V}$ and the peak potential of $0.88 \mathrm{~V}$, while in $0.1 \mathrm{M} \mathrm{HClO}_{4}$, the onset and half-wave potentials value $0.90 \mathrm{~V}$ and $0.76 \mathrm{~V}$, respectively. From XPS measurements, the peaks at $710.8 \mathrm{eV}$ and $780.6 \mathrm{eV}$ are assigned to $\mathrm{Fe}$ and Co respectively, which prove the existence of $\mathrm{Fe}-\mathrm{N}_{\mathrm{x}}$ and $\mathrm{Co}-\mathrm{N}_{\mathrm{x}}$ sites for providing high ORR performance. The durability may derive from the high graphitization of carbon structures, which is partly induced by Co. Similar active sites were also mentioned by Zhang et al. [87] by reporting a facile approach to $\mathrm{Fe}-\mathrm{Co}$ and nitrogen co-doped 3D porous graphitic carbon networks. A facile and rational two-step route is provided to prepare the efficient bimetal ORR catalyst, which exhibits a smaller onset potential $(1.05 \mathrm{~V})$ than the single-metal comparisons and a low Tafel slope $\left(65 \mathrm{mV} \mathrm{dec}^{-1}\right)$ in $0.1 \mathrm{M} \mathrm{KOH}$. The observed excellent ORR performance is owing to its hierarchical porosity and the synergistic effect of Fe and Co co-doping, which improve the reactant and electrolyte and provide accessible active sites including pyridinic $\mathrm{N}$ and metal-bonded $\mathrm{N}$. The development of single-atom catalysts provides a more detailed and intrinsic origin for the $\mathrm{M}-\mathrm{N}_{\mathrm{x}}$ sites. Wang et al. [52] designed a stable and efficient non-platinum catalyst for ORR based on $\mathrm{N}$-coordinated dual-metal sites. A host-guest strategy is developed to construct the material within the confined space of MOFs. A type of Co/Zn bimetallic MOF served as a host to absorb $\mathrm{FeCl}_{3}$ molecules with cavities. During the preparation, a double solvents method is applied to remit the diffusion resistance due to the narrow aperture. The X-ray adsorption fine structure spectroscopy and Mössbauer spectroscopic both prove the single-atom structure of the Fe and Co. From theoretical simulation and EXAFS results, the coordination structure is confirmed and shown in Figure 17a-f. The catalyst displays remarkable ORR activity, with the onset potential of $1.06 \mathrm{~V}$ and half-wave potential of $0.863 \mathrm{~V}$ in acid electrolyte. The ORR mechanism is simulated by employing DFT calculation and utilizing a simulated model with Fe-Co dual sites deposited on N-doped graphene, which is depicted in Figure 17g. The calculation indicates the break of the $\mathrm{O}-\mathrm{O}$ bond easily occurs on $\mathrm{Fe}-\mathrm{Co}$ dual site, the reason for which is owing to strong bond of $\mathrm{O}_{2}$ molecule on the dual site. The Fe-Co dual site provides two anchored position for the free $\mathrm{O}$ atoms, resulting in a stable output and exothermic reaction heat. Based on the calculation results, the rate-determining step of ORR is the hydrogenation step of changing adsorbed $\mathrm{OH}$ to $\mathrm{H}_{2} \mathrm{O}$ with an energy barrier of $0.26 \mathrm{eV}$, which is much lower than that of the rate-determining $\mathrm{O}-\mathrm{O}$ bond break on $\mathrm{Fe} / \mathrm{N}-\mathrm{C}(0.65 \mathrm{~V})$ and Pt-based materials $(\sim 0.80 \mathrm{eV})$. In summary, the $(\mathrm{Fe}, \mathrm{Co}) / \mathrm{N}-\mathrm{C}$ dual site favors breaking of the $\mathrm{O}-\mathrm{O}$ bond, leading to a higher ORR selectivity and efficiency to the four-electron path. 

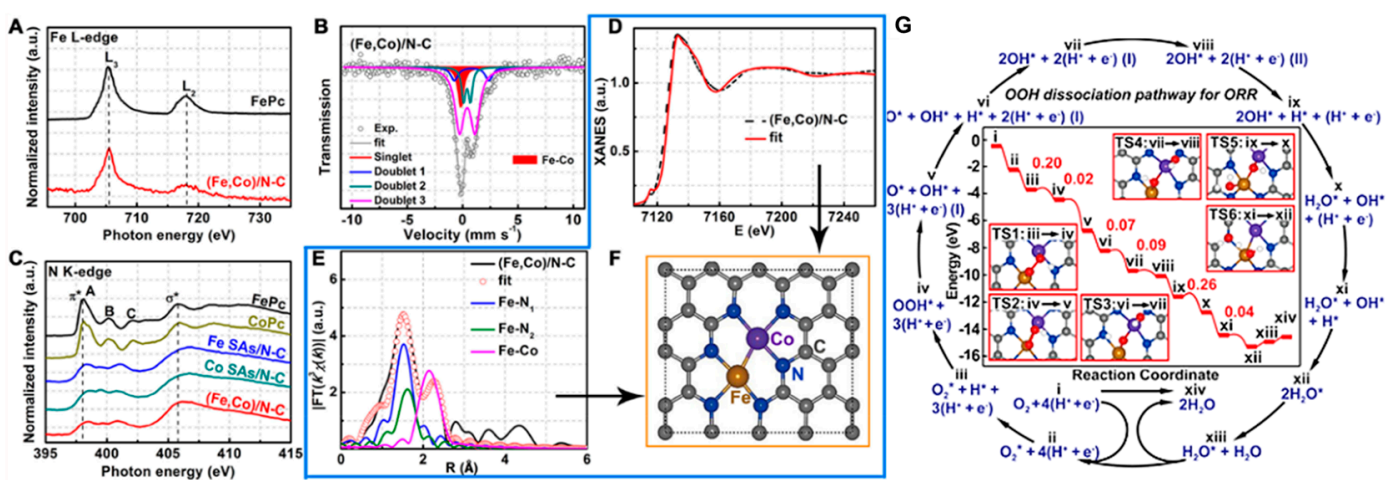

Figure 17. (a) XANES spectra of Fe L-edge of the prepared (Fe,Co)/N-C and FePc. (b) Fe Mössbauer transmission spectra measured at $298 \mathrm{~K}$ for $(\mathrm{Fe}, \mathrm{Co}) / \mathrm{N}-\mathrm{C}$, and fittings with spectral components. (c) $\mathrm{N}$ K-edge XAS spectra of Fe SAs/N-C, Co SAs/N-C, and (Fe,Co)/N-C. (d) Comparison between K-edge XANES experimental spectrum of $(\mathrm{Fe}, \mathrm{Co}) / \mathrm{N}-\mathrm{C}$ (black dashed line) and simulated spectrum obtained with depicted structure (solid red line). (e) Corresponding Fe K-edge EXAFS fittings of (Fe,Co)/N-C. (f) Hypothetical structures of Fe-Co dual sites. (g) Energies of intermediates and transition states in mechanism of ORR at $(\mathrm{Fe}, \mathrm{Co}) / \mathrm{N}-\mathrm{C}$ from density functional theory calculation (DFT), reproduced with permission [52]. Copyright American Chemical Society, 2017.

\section{Conclusions}

In spite of the enormous progress already achieved in fabricating bimetallic electrocatalysts with various methodologies, challenging opportunities for optimized and novel synthesis process, which deeply influence the catalytic activity, still remain to be grasped for electrocatalytic applications. In this review, we firstly categorize catalyst supports in the synthesis progresses, including carbon and MOF-based supports, which affect the surface and electronic structure, and further determine the mass transfer and electronic transport in the reactions. Methods such as hydrothermal and solvothermal treatment, electrospinning method, ball milling, and pyrolysis, etc., have been utilized in the construction of highly efficient $\mathrm{Fe} / \mathrm{Co}$ bimetallic nanoparticles or even atoms decorated with electrocatalysts. The introduction of the catalysts supports great improvements in the electrical conductivity and the texture structure of the catalytic materials, confines the nanoparticle size uniform distribution, and benefits the exposure of the active sites in the reaction process. Furthermore, we reviewed the outcomes of $\mathrm{Fe}, \mathrm{Co}$, and their derivatives, combined with hybrid materials for energy-related electrochemical reaction, including HER, ORR, and OER, emphasizing the synergistic effects between the bimetal content and their supports, and the correlation of the material structure with the electronic structure for enhanced electrocatalytic performances. The specific active structures and the mechanisms for the energy-related reactions are characterized and simulated. The synergistic coupling effect of substrates and the active metal phase further facilitates better charge transfer, and thus enhances the activity more forward. Incorporation of heteroatoms (N, P, B) into the lattice of carbon material and MOFs, altering the electronegativity of the support, is speculated to greatly ameliorate the electrocatalytic water splitting performance via modulating the electronic structure.

Therefore, the concepts in catalyst design, advanced approaches in determining active sites and intermediates, are imperative for the electrocatalysts. The molecule design, as well as the combination of computational and experimental methods, have significantly influenced understanding of the reaction mechanisms and led to the development of advanced electrocatalysts.

It may help to investigate the hybrid synthesis progress and material structure effect on the particle size and dispersion situation, metal-support interactions, charge transfer, and adsorbing energy of certain intermediates. However, the chemical modification of the catalyst with multi-atom doping and multilevel structure make the materials more complicated and difficult to identify actual active sites. Specifically, the single-atom catalysts combining both metals, especially those containing dual-metal sites as catalytic active positions, are still urgently needed. The theoretical significance of accurately 
identifying the catalytic active sites of the single-atom catalysts is promising and notable. However, to design and construct catalysts that could ideally link theoretical calculation and intrinsic properties of the material is still a tough challenge. Herein, it is critical to fill the gap between the theoretical models and experimental methods. Furthermore, considering the intrinsic properties of the transition bimetallic catalysts, more energy-related applications remain to be explored in width and depth.

Author Contributions: Conceptualization, K.L. and Y.L.; validation, W.P., G.Z. and F.Z.; resources, X.F.; writing—original draft preparation, K.L.; writing—review and editing, Y.L.; visualization, X.F.; funding acquisition, X.F. and Y.L.

Funding: This research was funded by the National Natural Science Funds, grant number 21676198, the Specialized Research Funds for the National Natural Science Foundation of China, grant number 21506157, and the Program of Introducing Talents of Discipline to Universities, grant number B06006.

Conflicts of Interest: The authors declare no conflict of interest.

\section{References}

1. Tao, L.; Wang, Y.; Zou, Y.; Zhang, N.; Zhang, Y.; Wu, Y.; Wang, Y.; Chen, R.; Wang, S. Charge Transfer Modulated Activity of Carbon-Based Electrocatalysts. Adv. Energy Mater. 2019, 1901227. [CrossRef]

2. Dong, D.; Wu, Z.; Wang, J.; Fu, G.; Tang, Y. Recent progress in $\mathrm{Co}_{9} \mathrm{~S}_{8}$-based materials for hydrogen and oxygen electrocatalysis. J. Mater. Chem. A 2019, 7, 16068-16088. [CrossRef]

3. Yan, Y.; Xia, B.Y.; Zhao, B.; Wang, X. A review on noble-metal-free bifunctional heterogeneous catalysts for overall electrochemical water splitting. J. Mater. Chem. A 2016, 4, 17587-17603. [CrossRef]

4. Ahmed, J.; Kumar, B.; Mugweru, A.M.; Trinh, P.; Ramanujachary, K.V.; Lofland, S.E.; Govind; Ganguli, A.K. Binary Fe-Co Alloy Nanoparticles Showing Significant Enhancement in Electrocatalytic Activity Compared with Bulk Alloys. J. Phys. Chem. C 2010, 114, 18779-18784. [CrossRef]

5. Peng, P.; Lin, X.-M.; Liu, Y.; Filatov, A.S.; Li, D.; Stamenkovic, V.R.; Yang, D.; Prakapenka, V.B.; Lei, A.; Shevchenko, E.V. Binary Transition-Metal Oxide Hollow Nanoparticles for Oxygen Evolution Reaction. ACS Appl. Mater. Interfaces 2018, 10, 24715-24724. [CrossRef]

6. Babar, P.; Lokhande, A.; Shin, H.H.; Pawar, B.; Gang, M.G.; Pawar, S.; Kim, J.H. Cobalt Iron Hydroxide as a Precious Metal-Free Bifunctional Electrocatalyst for Efficient Overall Water Splitting. Small 2018, 14, 1702568. [CrossRef]

7. Yang, J.; Zhu, G.; Liu, Y.; Xia, J.; Ji, Z.; Shen, X.; Wu, S. $\mathrm{Fe}_{3} \mathrm{O}_{4}$-Decorated $\mathrm{Co}_{9} \mathrm{~S}_{8}$ Nanoparticles in Situ Grown on Reduced Graphene Oxide: A New and Efficient Electrocatalyst for Oxygen Evolution Reaction. Adv. Funct. Mater. 2016, 26, 4712-4721. [CrossRef]

8. Kibsgaard, J.; Tsai, C.; Chan, K.; Benck, J.D.; Norskov, J.K.; Abild-Pedersen, F.; Jaramillo, T.F. Designing an improved transition metal phosphide catalyst for hydrogen evolution using experimental and theoretical trends. Energy Environ. Sci. 2015, 8, 3022-3029. [CrossRef]

9. Jo, C.; Lee, J.I.; Jang, Y. Electronic and Magnetic Properties of Ultrathin Fe-Co Alloy Nanowires. Chem. Mater. 2005, 17, 2667-2671. [CrossRef]

10. Bergmann, A.; Martinez-Moreno, E.; Teschner, D.; Chernev, P.; Gliech, M.; de Araujo, J.F.; Reier, T.; Dau, H.; Strasser, P. Reversible amorphization and the catalytically active state of crystalline $\mathrm{Co}_{3} \mathrm{O}_{4}$ during oxygen evolution. Nat. Commun. 2015, 6, 8625. [CrossRef]

11. Song, F.; Hu, X. Exfoliation of layered double hydroxides for enhanced oxygen evolution catalysis. Nat. Commun. 2014, 5, 4477. [CrossRef] [PubMed]

12. Jin, H.; Mao, S.; Zhan, G.; Xu, F.; Bao, X.; Wang, Y. Fe incorporated $\alpha-\mathrm{Co}(\mathrm{OH})_{2}$ nanosheets with remarkably improved activity towards the oxygen evolution reaction. J. Mater. Chem. A 2017, 5, 1078-1084. [CrossRef]

13. Yang, F.; Sliozberg, K.; Sinev, I.; Antoni, H.; Baehr, A.; Ollegott, K.; Xia, W.; Masa, J.; Gruenert, W.; Roldan Cuenya, B.; et al. Synergistic Effect of Cobalt and Iron in Layered Double Hydroxide Catalysts for the Oxygen Evolution Reaction. Chemsuschem 2017, 10, 156-165. [CrossRef] [PubMed]

14. Burke, M.S.; Kast, M.G.; Trotochaud, L.; Smith, A.M.; Boettcher, S.W. Cobalt-Iron (Oxy)hydroxide Oxygen Evolution Electrocatalysts: The Role of Structure and Composition on Activity, Stability, and Mechanism. J. Am. Chem. Soc. 2015, 137, 3638-3648. [CrossRef] [PubMed] 
15. Griboval-Constant, A.; Butel, A.; Ordomsy, V.V.; Chernavskii, P.A.; Khodakova, A.Y. Cobalt and iron species in alumina supported bimetallic catalysts for Fischer-Tropsch reaction. Appl. Catal. A 2014, 481, 116-126. [CrossRef]

16. Antonio Diaz, J.; Akhavan, H.; Romero, A.; Maria Garcia-Minguillan, A.; Romero, R.; Giroir-Fendler, A.; Luis Valverde, J. Cobalt and iron supported on carbon nanofibers as catalysts for Fischer-Tropsch synthesis. Fuel Process. Technol. 2014, 128, 417-424. [CrossRef]

17. Masa, J.; Weide, P.; Peeters, D.; Sinev, I.; Xia, W.; Sun, Z.; Somsen, C.; Muhler, M.; Schuhmann, W. Amorphous Cobalt Boride $\left(\mathrm{CO}_{2} \mathrm{~B}\right)$ as a Highly Efficient Nonprecious Catalyst for Electrochemical Water Splitting: Oxygen and Hydrogen Evolution. Adv. Energy Mater. 2016, 6, 1502313. [CrossRef]

18. Chen, H.; Ouyang, S.; Zhao, M.; Li, Y.; Ye, J. Synergistic Activity of Co and Fe in Amorphous Cox-Fe-B Catalyst for Efficient Oxygen Evolution Reaction. ACS Appl. Mater. Interfaces 2017, 9, 40333-40343. [CrossRef]

19. Wu, Z.; Nie, D.; Song, M.; Jiao, T.; Fu, G.; Liu, X. Facile synthesis of Co-Fe-B-P nanochains as an efficient bifunctional electrocatalyst for overall water-splitting. Nanoscale 2019, 11, 7506-7512. [CrossRef]

20. Yang, L.; Guo, Z.; Huang, J.; Xi, Y.; Gao, R.; Su, G.; Wang, W.; Cao, L.; Dong, B. Vertical Growth of 2D Amorphous $\mathrm{FePO}_{4}$ Nanosheet on Ni Foam: Outer and Inner Structural Design for Superior Water Splitting. Adv. Mater. 2017, 29, 1704574. [CrossRef]

21. Yang, Y.; Zhuang, L.; Lin, R.; Li, M.; Xu, X.; Rufford, T.E.; Zhu, Z. A facile method to synthesize boron-doped $\mathrm{Ni} /$ Fe alloy nano-chains as electrocatalyst for water oxidation. J. Power Sources 2017, 349, 68-74. [CrossRef]

22. Li, Y.; Fan, X.; Qi, J.; Ji, J.; Wang, S.; Zhang, G.; Zhang, F. Palladium nanoparticle-graphene hybrids as active catalysts for the Suzuki reaction. Nano Res. 2010, 3, 429-437. [CrossRef]

23. Zhang, J.; Ma, J.; Fan, X.; Peng, W.; Zhang, G.; Zhang, F.; Li, Y. Graphene supported Au-Pd-Fe $\mathrm{O}_{4}$ alloy trimetallic nanoparticles with peroxidase-like activities as mimic enzyme. Catal. Commun. 2017, 89, 148-151. [CrossRef]

24. Mattioli, G.; Giannozzi, P.; Bonapasta, A.A.; Guidonili, L. Reaction Pathways for Oxygen Evolution Promoted by Cobalt Catalyst. J. Am. Chem. Soc. 2013, 135, 15353-15363. [CrossRef] [PubMed]

25. Han, X.; Yu, C.; Zhou, S.; Zhao, C.; Huang, H.; Yang, J.; Liu, Z.; Zhao, J.; Qiu, J. Ultrasensitive Iron-Triggered Nanosized Fe-CoOOH Integrated with Graphene for Highly Efficient Oxygen Evolution. Adv. Energy Mater. 2017, 7, 1602148. [CrossRef]

26. Jiao, Y.; Zheng, Y.; Jaroniec, M.; Qiao, S.Z. Origin of the Electrocatalytic Oxygen Reduction Activity of Graphene-Based Catalysts: A Roadnnap to Achieve the Best Performance. J. Am. Chem. Soc. 2014, 136, 4394-4403. [CrossRef] [PubMed]

27. Wu, N.; Lei, Y.; Wang, Q.; Wang, B.; Han, C.; Wang, Y. Facile synthesis of FeCo@NC core-shell nanospheres supported on graphene as an efficient bifunctional oxygen electrocatalyst. Nano Res. 2017, 10, 2332-2343. [CrossRef]

28. Seo, W.S.; Lee, J.H.; Sun, X.; Suzuki, Y.; Mann, D.; Liu, Z.; Terashima, M.; Yang, P.C.; McConnell, M.V.; Nishimura, D.G.; et al. FeCo/graphitic-shell nanocrystals as advanced magnetic-resonance-imaging and near-infrared agents. Nat. Mater. 2006, 5, 971-976. [CrossRef]

29. Zhu, S.J.; Zhang, J.H.; Qiao, C.Y.; Tang, S.J.; Li, Y.F.; Yuan, W.J.; Li, B.; Tian, L.; Liu, F.; Hu, R.; et al. Strongly green-photoluminescent graphene quantum dots for bioimaging applications. Chem. Commun. 2011, 47, 6858-6860. [CrossRef]

30. Navalon, S.; Dhakshinamoorthy, A.; Alvaro, M.; Garcia, H. Carbocatalysis by Graphene-Based Materials. Chem. Rev. 2014, 114, 6179-6212. [CrossRef]

31. Palaniselvam, T.; Kashyap, V.; Bhange, S.N.; Baek, J.-B.; Kurungot, S. Nanoporous Graphene Enriched with $\mathrm{Fe} / \mathrm{Co}-\mathrm{N}$ Active Sites as a Promising Oxygen Reduction Electrocatalyst for Anion Exchange Membrane Fuel Cells. Adv. Funct. Mater. 2016, 26, 2150-2162. [CrossRef]

32. Palaniselvam, T.; Valappil, M.O.; Illathvalappil, R.; Kurungot, S. Nanoporous graphene by quantum dots removal from graphene and its conversion to a potential oxygen reduction electrocatalyst via nitrogen doping. Energy Environ. Sci. 2014, 7, 1059-1067. [CrossRef]

33. Yang, X.-F.; Wang, A.; Qiao, B.; Li, J.; Liu, J.; Zhang, T. Single-Atom Catalysts: A New Frontier in Heterogeneous Catalysis. Acc. Chem. Res. 2013, 46, 1740-1748. [CrossRef] [PubMed]

34. Qiao, B.T.; Wang, A.Q.; Yang, X.F.; Allard, L.F.; Jiang, Z.; Cui, Y.T.; Liu, J.Y.; Li, J.; Zhang, T. Single-atom catalysis of $\mathrm{CO}$ oxidation using Pt-1/FeO . Nat. Chem. 2011, 3, 634-641. [CrossRef] [PubMed] 
35. Bakandritsos, A.; Kadam, R.G.; Kumar, P.; Zoppellaro, G.; Medved, M.; Tucek, J.; Montini, T.; Tomanec, O.; Andryskova, P.; Drahos, B.; et al. Mixed-Valence Single-Atom Catalyst Derived from Functionalized Graphene. Adv. Mater. 2019, 31, e1900323. [CrossRef] [PubMed]

36. Wang, W.; Babu, D.D.; Huang, Y.; Lv, J.; Wang, Y.; Wu, M. Atomic dispersion of Fe/Co/N on graphene by ball-milling for efficient oxygen evolution reaction. Int. J. Hydrog. Energy 2018, 43, 10351-11035. [CrossRef]

37. Li, M.; Liu, T.; Bo, X.; Zhou, M.; Guo, L. A novel flower-like architecture of FeCo@NC-functionalized ultra-thin carbon nanosheets as a highly efficient 3D bifunctional electrocatalyst for full water splitting. J. Mater. Chem. A 2017, 5, 5413-5425. [CrossRef]

38. Samanta, A.; Raj, C.R. Catalyst Support in Oxygen Electrocatalysis: A Case Study with CoFe Alloy Electrocatalyst. J. Phys. Chem. C 2018, 122, 15843-15852. [CrossRef]

39. Liu, Q.; Cao, S.; Qiu, Y.; Zhao, L. Bimetallic Fe-Co promoting one-step growth of hierarchical nitrogen-doped carbon nanotubes/nanofibers for highly efficient oxygen reduction reaction. Mater. Sci. Eng. B 2017, 223, 159-166. [CrossRef]

40. Li, C.; Wu, M.; Liu, R. High-performance bifunctional oxygen electrocatalysts for zinc-air batteries over mesoporous Fe/Co-N-C nanofibers with embedding FeCo alloy nanoparticles. Appl. Catal. B 2019, 244, 150-158. [CrossRef]

41. Yan, Y.; Miao, J.; Yang, Z.; Xiao, F.-X.; Yang, H.B.; Liu, B.; Yang, Y. Carbon nanotube catalysts: Recent advances in synthesis, characterization and applications. Chem. Soc. Rev. 2015, 44, 3295-3346. [CrossRef] [PubMed]

42. Su, C.-Y.; Cheng, H.; Li, W.; Liu, Z.-Q.; Li, N.; Hou, Z.; Bai, F.-Q.; Zhang, H.-X.; Ma, T.-Y. Atomic Modulation of FeCo-Nitrogen-Carbon Bifunctional Oxygen Electrodes for Rechargeable and Flexible All-Solid-State Zinc-Air Battery. Adv. Energy Mater. 2017, 7, 1602420. [CrossRef]

43. Yang, Y.; Lun, Z.; Xia, G.; Zheng, F.; He, M.; Chen, Q. Non-precious alloy encapsulated in nitrogen-doped graphene layers derived from MOFs as an active and durable hydrogen evolution reaction catalyst. Energy Environ. Sci. 2015, 8, 3563-3571. [CrossRef]

44. Lian, Y.; Sun, H.; Wang, X.; Qi, P.; Mu, Q.; Chen, Y.; Ye, J.; Zhao, X.; Deng, Z.; Peng, Y. Carved nanoframes of cobalt-iron bimetal phosphide as a bifunctional electrocatalyst for efficient overall water splitting. Chem. Sci. 2019, 10, 464-474. [CrossRef] [PubMed]

45. Zhang, W.; Zhang, H.; Luo, R.; Zhang, M.; Yan, X.; Sun, X.; Shen, J.; Han, W.; Wang, L.; Li, J. Prussian blue analogues-derived bimetallic iron-cobalt selenides for efficient overall water splitting. J. Colloid Interface Sci. 2019, 548, 48-55. [CrossRef] [PubMed]

46. Hu, C.; Zhang, L.; Zhao, Z.-J.; Li, A.; Chang, X.; Gong, J. Synergism of Geometric Construction and Electronic Regulation: 3D Se-(NiCo) $\mathrm{S}_{\mathrm{x}} /(\mathrm{OH})_{\mathrm{x}}$ Nanosheets for Highly Efficient Overall Water Splitting. Adv. Mater. 2018, 30, 1705538. [CrossRef] [PubMed]

47. Chen, J.; Liu, J.; Xie, J.-Q.; Ye, H.; Fu, X.-Z.; Sun, R.; Wong, C.-P. Co-Fe-P nanotubes electrocatalysts derived from metal-organic frameworks for efficient hydrogen evolution reaction under wide $\mathrm{pH}$ range. Nano Energy 2019, 56, 225-233. [CrossRef]

48. Wang, J.; Xu, F.; Jin, H.; Chen, Y.; Wang, Y. Non-Noble Metal-based Carbon Composites in Hydrogen Evolution Reaction: Fundamentals to Applications. Adv. Mater. 2017, 29, 1605838. [CrossRef]

49. Wang, X.; Yu, L.; Guan, B.Y.; Song, S.; Lou, X.W. Metal-Organic Framework Hybrid-Assisted Formation of $\mathrm{Co}_{3} \mathrm{O}_{4} / \mathrm{Co}-\mathrm{Fe}$ Oxide Double-Shelled Nanoboxes for Enhanced Oxygen Evolution. Adv. Mater. 2018, 30, 1801211. [CrossRef] [PubMed]

50. Trotochaud, L.; Young, S.L.; Ranney, J.K.; Boettcher, S.W. Nickel-Iron Oxyhydroxide Oxygen-Evolution Electrocatalysts: The Role of Intentional and Incidental Iron Incorporation. J. Am. Chem. Soc. 2014, 136, 6744-6753. [CrossRef]

51. Chen, W.X.; Pei, J.J.; He, C.T.; Wan, J.W.; Ren, H.L.; Zhu, Y.Q.; Wang, Y.; Dong, J.C.; Tian, S.B.; Cheong, W.C.; et al. Rational Design of Single Molybdenum Atoms Anchored on N-Doped Carbon for Effective Hydrogen Evolution Reaction. Angew. Chem. Int. Edit. 2017, 56, 16086-16090. [CrossRef] [PubMed]

52. Wang, J.; Huang, Z.; Liu, W.; Chang, C.; Tang, H.; Li, Z.; Chen, W.; Jia, C.; Yao, T.; Wei, S.; et al. Design of N-Coordinated Dual-Metal Sites: A Stable and Active Pt-Free Catalyst for Acidic Oxygen Reduction Reaction. J. Am. Chem. Soc. 2017, 139, 17281-17284. [CrossRef] [PubMed]

53. Cook, T.R.; Dogutan, D.K.; Reece, S.Y.; Surendranath, Y.; Teets, T.S.; Nocera, D.G. Solar energy supply and storage for the legacy and nonlegacy worlds. Chem. Rev. 2010, 110, 6474-6502. [CrossRef] [PubMed] 
54. Du, N.; Wang, C.; Wang, X.; Lin, Y.; Jiang, J.; Xiong, Y. Trimetallic TriStar Nanostructures: Tuning Electronic and Surface Structures for Enhanced Electrocatalytic Hydrogen Evolution. Adv. Mater. 2016, 28, 2077-2084. [CrossRef] [PubMed]

55. Müller, C.I.; Sellschopp, K.; Tegel, M.; Rauscher, T.; Kieback, B.; Röntzsch, L. The activity of nanocrystalline Fe-based alloys as electrode materials for the hydrogen evolution reaction. J. Power Sources 2016, 304, $196-206$. [CrossRef]

56. Liu, W.; Du, K.; Liu, L.; Zhang, J.; Zhu, Z.; Shao, Y.; Li, M. One-step electroreductively deposited iron-cobalt composite films as efficient bifunctional electrocatalysts for overall water splitting. Nano Energy 2017, 38, 576-584. [CrossRef]

57. Zhang, X.; Zhang, X.; Xu, H.; Wu, Z.; Wang, H.; Liang, Y. Iron-Doped Cobalt Monophosphide Nanosheet/ Carbon Nanotube Hybrids as Active and Stable Electrocatalysts for Water Splitting. Adv. Funct. Mater. 2017, 27, 1606635. [CrossRef]

58. Guo, X.; Yu, X.; Feng, Z.; Liang, J.; Li, Q.; Lv, Z.; Liu, B.; Hao, C.; Li, G. Intercalation Synthesis of Prussian Blue Analogue Nanocone and Their Conversion into Fe-Doped $\mathrm{Co}_{x} \mathrm{P}$ Nanocone for Enhanced Hydrogen Evolution. ACS Sustain. Chem. Eng. 2018, 6, 8150-8158. [CrossRef]

59. Li, F.; Bu, Y.; Lv, Z.; Mahmood, J.; Han, G.-F.; Ahmad, I.; Kim, G.; Zhong, Q.; Baek, J.-B. Porous Cobalt Phosphide Polyhedrons with Iron Doping as an Efficient Bifunctional Electrocatalyst. Small 2017, 13, 1701167. [CrossRef] [PubMed]

60. Cao, L.M.; Hu, Y.W.; Tang, S.F.; Iljin, A.; Wang, J.W.; Zhang, Z.M.; Lu, T.B. Fe-CoP Electrocatalyst Derived from a Bimetallic Prussian Blue Analogue for Large-Current-Density Oxygen Evolution and Overall Water Splitting. Adv. Sci. 2018, 5, 1800949. [CrossRef] [PubMed]

61. Kim, H.; Oh, S.; Cho, E.; Kwon, H. 3D Porous Cobalt-Iron-Phosphorus Bifunctional Electrocatalyst for the Oxygen and Hydrogen Evolution Reactions. ACS Sustain. Chem. Eng. 2018, 6, 6305-6311. [CrossRef]

62. Kuo, T.-R.; Chen, W.-T.; Liao, H.-J.; Yang, Y.-H.; Yen, H.-C.; Liao, T.-W.; Wen, C.-Y.; Lee, Y.-C.; Chen, C.-C.; Wang, D.-Y. Improving Hydrogen Evolution Activity of Earth-Abundant Cobalt-Doped Iron Pyrite Catalysts by Surface Modification with Phosphide. Small 2017, 13, 1603356. [CrossRef] [PubMed]

63. Liu, Y.; Li, F.; Yang, H.; Li, J.; Ma, P.; Zhu, Y.; Ma, J. Two-Step Synthesis of Cobalt Iron Alloy Nanoparticles Embedded in Nitrogen-Doped Carbon Nanosheets/Carbon Nanotubes for the Oxygen Evolution Reaction. ChemSusChem 2018, 11, 2358-2366. [CrossRef] [PubMed]

64. Liu, X.; Wang, L.; Yu, P.; Tian, C.; Sun, F.; Ma, J.; Li, W.; Fu, H. A Stable Bifunctional Catalyst for Rechargeable Zinc-Air Batteries: Iron-Cobalt Nanoparticles Embedded in a Nitrogen-Doped 3D Carbon Matrix. Angew. Chem. Int. Ed. Engl. 2018, 57, 16166-16170. [CrossRef] [PubMed]

65. Feng, X.; Bo, X.; Guo, L. $\operatorname{CoM}(\mathrm{M}=\mathrm{Fe}, \mathrm{Cu}, \mathrm{Ni})$-embedded nitrogen-enriched porous carbon framework for efficient oxygen and hydrogen evolution reactions. J. Power Sources 2018, 389, 249-259. [CrossRef]

66. Zhu, X.; Jin, T.; Tian, C.; Lu, C.; Liu, X.; Zeng, M.; Zhuang, X.; Yang, S.; He, L.; Liu, H.; et al. In Situ Coupling Strategy for the Preparation of FeCo Alloys and $\mathrm{Co}_{4} \mathrm{~N}$ Hybrid for Highly Efficient Oxygen Evolution. Adv. Mater. 2017, 29, 1704091. [CrossRef]

67. Li, T.; Lu, Y.; Zhao, S.; Gao, Z.-D.; Song, Y.-Y. $\mathrm{Co}_{3} \mathrm{O}_{4}$-doped $\mathrm{Co} / \mathrm{CoFe}$ nanoparticles encapsulated in carbon shells as bifunctional electrocatalysts for rechargeable Zn-Air batteries. J. Mater. Chem. A 2018, 6, 3730-3737. [CrossRef]

68. Kim, B.; Park, I.; Yoon, G.; Kim, J.S.; Kim, H.; Kang, K. Atomistic Investigation of Doping Effects on Electrocatalytic Properties of Cobalt Oxides for Water Oxidation. Adv. Sci. 2018, 5, 1801632. [CrossRef]

69. Indra, A.; Menezes, P.W.; Sahraie, N.R.; Bergmann, A.; Das, C.; Tallarida, M.; Schmeisser, D.; Strasser, P.; Driess, M. Unification of Catalytic Water Oxidation and Oxygen Reduction Reactions: Amorphous Beat Crystalline Cobalt Iron Oxides. J. Am. Chem. Soc. 2014, 136, 17530-17536. [CrossRef]

70. Chen, W.; Wang, H.; Li, Y.; Liu, Y.; Sun, J.; Lee, S.; Lee, J.-S.; Cui, Y. In Situ Electrochemical Oxidation Tuning of Transition Metal Disulfides to Oxides for Enhanced Water Oxidation. ACS Cent. Sci. 2015, 1, $244-251$. [CrossRef]

71. Zhang, Y.; Gao, T.; Jin, Z.; Chen, X.; Xiao, D. A robust water oxidation electrocatalyst from amorphous cobalt-iron bimetallic phytate nanostructures. J. Mater. Chem. A 2016, 4, 15888-15895. [CrossRef]

72. Liu, K.; Zhang, C.; Sun, Y.; Zhang, G.; Shen, X.; Zou, F.; Zhang, H.; Wu, Z.; Wegener, E.C.; Taubert, C.J.; et al. High-Performance Transition Metal Phosphide Alloy Catalyst for Oxygen Evolution Reaction. ACS Nano 2018, 12, 158-167. [CrossRef] 
73. Shen, J.-Q.; Liao, P.-Q.; Zhou, D.-D.; He, C.-T.; Wu, J.-X.; Zhang, W.-X.; Zhang, J.-P.; Chen, X.-M. Modular and Stepwise Synthesis of a Hybrid Metal-Organic Framework for Efficient Electrocatalytic Oxygen Evolution. J. Am. Chem. Soc. 2017, 139, 1778-1781. [CrossRef]

74. Chen, Y.; Ji, S.; Chen, C.; Peng, Q.; Wang, D.; Li, Y. Single-Atom Catalysts: Synthetic Strategies and Electrochemical Applications. Joule 2018, 2, 1242-1264. [CrossRef]

75. Li, S.; Cheng, C.; Zhao, X.; Schmidt, J.; Thomas, A. Active Salt/Silica-Templated 2D Mesoporous FeCo-N -Carbon as Bifunctional Oxygen Electrodes for Zinc-Air Batteries. Angew. Chem. Int. Ed. Engl. 2018, 57, 1856-1862. [CrossRef]

76. Sultan, S.; Tiwari, J.N.; Jang, J.-H.; Harzandi, A.M.; Salehnia, F.; Yoo, S.J.; Kim, K.S. Highly Efficient Oxygen Reduction Reaction Activity of Graphitic Tube Encapsulating Nitrided $\mathrm{Co}_{\mathrm{x}} \mathrm{Fe}_{\mathrm{y}}$ Alloy. Adv. Energy Mater. 2018, 8, 1801002. [CrossRef]

77. Lim, S.H.; Li, Z.; Poh, C.K.; Lai, L.; Lin, J. Highly active non-precious metal catalyst based on poly(vinylpyrrolidone)-wrapped carbon nanotubes complexed with iron-cobalt metal ions for oxygen reduction reaction. J. Power Sources 2012, 214, 15-20. [CrossRef]

78. Guan, B.Y.; Lu, Y.; Wang, Y.; Wu, M.; Lou, X.W.D. Porous Iron-Cobalt Alloy/Nitrogen-Doped Carbon Cages Synthesized via Pyrolysis of Complex Metal-Organic Framework Hybrids for Oxygen Reduction. Adv. Funct. Mater. 2018, 28, 1706738. [CrossRef]

79. Tan, M.; He, T.; Liu, J.; Wu, H.; Li, Q.; Zheng, J.; Wang, Y.; Sun, Z.; Wang, S.; Zhang, Y. Supramolecular bimetallogels: A nanofiber network for bimetal/nitrogen co-doped carbon electrocatalysts. J. Mater. Chem. A 2018, 6, 8227-8232. [CrossRef]

80. Wang, J.; Xin, H.L.; Zhu, J.; Liu, S.; Wu, Z.; Wang, D. 3D hollow structured Co2FeO4/MWCNT as an efficient non-precious metal electrocatalyst for oxygen reduction reaction. J. Mater. Chem. A 2015, 3, 1601-1608. [CrossRef]

81. Kim, J.; Gwon, O.; Kwon, O.; Mahmood, J.; Kim, C.; Yang, Y.; Lee, H.; Lee, J.H.; Jeong, H.Y.; Baek, J.B.; et al. Synergistic Coupling Derived Cobalt Oxide with Nitrogenated Holey Two-Dimensional Matrix as an Efficient Bifunctional Catalyst for Metal-Air Batteries. ACS Nano 2019, 13, 5502-5512. [CrossRef]

82. Wang, C.-H.; Yang, C.-W.; Lin, Y.-C.; Chang, S.-T.; Chang, S.L.Y. Cobalt-iron (II, III) oxide hybrid catalysis with enhanced catalytic activities for oxygen reduction in anion exchange membrane fuel cell. J. Power Sources 2015, 277, 147-154. [CrossRef]

83. Jin, Y.Q.; Lin, Z.; Zhong, R.; Huang, J.; Liang, G.; Li, J.; Jin, Y.; Meng, H. Cobalt iron carbonate hydroxide hydrate on $3 \mathrm{D}$ porous carbon as active and stable bifunctional oxygen electrode for $\mathrm{Zn}$-air battery. J. Power Sources 2018, 402, 388-393. [CrossRef]

84. Sun, K.; Li, J.; Huang, L.; Ji, S.; Kannan, P.; Li, D.; Liu, L.; Liao, S. Biomass-derived 3D hierarchical N-doped porous carbon anchoring cobalt-iron phosphide nanodots as bifunctional electrocatalysts for $\mathrm{Li}_{2}$ batteries. J. Power Sources 2019, 412, 433-441. [CrossRef]

85. Zhao, Y.; Watanabe, K.; Hashimoto, K. Efficient oxygen reduction by a Fe/Co/C/N nano-porous catalyst in neutral media. J. Mater. Chem. A 2013, 1, 1450-1456. [CrossRef]

86. Lin, Q.; Bu, X.; Kong, A.; Mao, C.; Bu, F.; Feng, P. Heterometal-Embedded Organic Conjugate Frameworks from Alternating Monomeric Iron and Cobalt Metalloporphyrins and Their Application in Design of Porous Carbon Catalysts. Adv. Mater. 2015, 27, 3431-3436. [CrossRef]

87. Zhang, Z.; Dou, M.; Liu, H.; Dai, L.; Wang, F. A Facile Route to Bimetal and Nitrogen-Codoped 3D Porous Graphitic Carbon Networks for Efficient Oxygen Reduction. Small 2016, 12, 4193-4199. [CrossRef]

(C) 2019 by the authors. Licensee MDPI, Basel, Switzerland. This article is an open access article distributed under the terms and conditions of the Creative Commons Attribution (CC BY) license (http://creativecommons.org/licenses/by/4.0/). 